\title{
DETERMINAÇÃO DAS PREVISÕES DE TEMPERATURAS MÍNIMAS E MÁXIMAS A PARTIR DO HISTÓRICO DAS PREVISÕES DE TEMPO POR CONJUNTO DO CPTEC
}

\author{
MARIA CRISTINA LEMOS DA SILVA, ANTÔNIO MARCOS MENDONÇA e JOSÉ PAULO BONATTI
}

\author{
Centro de Previsão de Tempo e Estudos Climáticos - CPTEC \\ Rod. Pres. Dutra - Km 40 - SP-RJ - 12630-000 - Cachoeira Paulista - SP, Brasil \\ cristina@cptec.inpe.br \\ mendonca@cptec.inpe.br \\ bonatti@cptec.inpe.br
}

Recebido Junho 2007 - Aceito Setembro 2008

\begin{abstract}
RESUMO
A técnica de previsão de tempo por conjunto representa uma tentativa de aumentar a previsibilidade dos modelos dinâmicos da atmosfera. Uma forma simples de produzir previsões de tempo por conjunto é adicionar pequenas perturbações às condições iniciais do modelo, e integrá-lo partindo de cada condição inicial perturbada para produzir um conjunto de previsões. O objetivo do presente estudo é apresentar uma metodologia desenvolvida para determinar as temperaturas mínimas e máximas à superfície, a partir de informações do histórico do ponto de grade das previsões por conjunto do Centro de Previsão de Tempo e Estudos Climáticos (CPTEC) sobre o Brasil. Os resultados indicaram que o modelo de circulação geral da atmosfera do CPTEC apresenta temperaturas mínimas (máximas) sistematicamente mais altas (baixas) dos que as observadas. Um método de correção estatística, baseado no viés médio das 15 previsões mais recentes do modelo, foi aplicado para corrigir as previsões do conjunto. Tais correções aumentam o desempenho das previsões, como é indicado pelos índices estatísticos rms, bias e coeficiente de correlação de anomalia.
\end{abstract}

Palavras-Chave: Temperatura mínima, temperatura máxima, previsão de tempo por conjunto.

ABSTRACT: DETERMINATION OF MINIMUM AND MAXIMUM TEMPERATURE FORECASTS FROM GRID-HISTORY OF CPTEC ENSEMBLE WEATHER PREDICTION

The ensemble weather forecast approach represents an attempt to extend the predictability of the dynamic atmospheric models. A simple away to produce ensemble weather prediction is to run the weather model starting from a set of slightly perturbed initial conditions. The objective of the present study is to present a methodology to determine the minimum and maximum surface temperatures using the grid history of the ensemble forecasts over Brazil available at the Center for Weather Forecasting and Climate Studies (CPTEC). The results indicated that forecasts of minimum (maximum) temperatures from the CPTEC general circulation model exhibit systematically higher (lower) temperatures than observed. A statistical correction based on the bias of the fifteenth earlier forecasts was used to improve the ensemble predictions. Such corrections enhance the performance of the forecasts as measured by statistical indexes as rms, bias and anomaly correlation coefficient. Keywords: Minimum temperature, maximum temperature, ensemble weather forecasting. 


\section{INTRODUÇÃO}

A idéia básica da previsão de tempo por conjunto ou "ensemble" é diminuir o impacto da incerteza do estado inicial da atmosfera na previsão final, tomando um conjunto de estados iniciais ligeiramente diferentes da análise inicial e gerando uma saída do modelo para cada um dos estados desse conjunto. Vale ressaltar que cada execução do modelo é determinística, isto é, definida de modo único pelas condições iniciais, mas o conjunto de previsões tomadas a partir de estados iniciais ligeiramente diferentes da análise, fornece uma descrição do caráter caótico da atmosfera (Coutinho, 1999). Um dos propósitos da previsão por conjunto é identificar as incertezas da previsão de tempo e aumentar a exatidão da previsão média (Sivillo et al., 1997).

O sistema de previsão de tempo global por conjunto do Centro de Previsão de Tempo e Estudos Climáticos (CPTEC) teve sua origem no trabalho de dissertação de mestrado de Coutinho (1999). Em seu trabalho foi utilizado o método baseado em funções ortogonais empíricas (EOF), denominado método-EOF (Zhang e Krishnamurti, 1999), para produzir as condições iniciais perturbadas. Neste método, supõe-se que o crescimento das perturbações seja aproximadamente linear nas primeiras 36 horas de integração do modelo, desta forma, o modo de crescimento mais rápido, também chamado de perturbação ótima, pode ser calculado através do cálculo das EOFs de uma série temporal formada pelas diferenças entre uma previsão de controle (determinística) e uma previsão partindo de uma condição inicial perturbada com valores aleatórios. Em outubro de 2001, o CPTEC iniciou operacionalmente a previsão de tempo global por conjunto utilizando o métodoEOF para perturbar as condições iniciais na região tropical (Mendonça e Bonatti, 2002). Diariamente, são realizadas duas execuções das previsões de tempo por conjunto, uma a partir das condições iniciais das 00:00 GMT e outra das 12:00 GMT. Cada rodada representa um conjunto de 15 simulações do MCGACPTEC, integradas até o prazo de 15 dias, numa resolução de aproximadamente 100x100 km próximo dos trópicos.

O MCGA-CPTEC teve sua origem no National Centers for Environmental Prediction (NCEP) e foi modificado pelo Center for Ocean-Land-Atmosphere Studies (COLA) nas décadas de 80/90. Este modelo é baseado na solução espectral das equações primitivas da dinâmica, na forma de divergência $e$ vorticidade, temperatura virtual, umidade específica e logaritmo da pressão à superfície, e na inclusão dos processos subgrade a partir de parametrizações. As equações são discretizadas em coordenadas esféricas na horizontal, e em coordenada sigma, na vertical. Possui truncamento triangular, e tem condições de contorno dadas por velocidade vertical sigma nula no topo e na superfície, e usa topografia espectralmente truncada (Kinter et al., 1997 e Bonatti, 1996).
O Brasil, pelas suas dimensões continentais, possui uma diversificação climática bem ampla, influenciada pela sua configuração geográfica, sua significativa extensão costeira, seu relevo e a dinâmica das massas de ar sobre seu território. Esse último fator assume grande importância, pois atua diretamente sobre as temperaturas (Climanálise, 1996).

As regiões subtropical e extratropical da América do Sul são afetadas pela passagem de massas de ar frio principalmente durante o inverno (Varejão-Silva, 2001). Quedas acentuadas de temperatura podem ser observadas após o estabelecimento deste sistema sobre determinada região (Fedorova, 1999). No Brasil, as regiões mais afetadas pela entrada de massas de ar frio são o Sul, Sudeste e Centro-Oeste (Varejão-Silva, 2001). Geadas podem trazer enormes prejuízos para o setor agrícola destas regiões, bem como pode haver significativo desconforto para a população devido às baixas temperaturas. Por outro lado, algumas regiões turísticas, tais como: as serras Gaúcha e Catarinense, bem como a cidade de Campos do Jordão, no Estado de São Paulo, são famosas por explorarem justamente o período de inverno. Da mesma forma, picos de temperatura podem trazer prejuízos para a agricultura, bem como danos à saúde da população. Por outro lado, o setor tropical do Brasil apresenta menor amplitude térmica do que as demais regiões. Neste caso, são as previsões de temperaturas máximas que têm um valor sócio-econômico maior.

Desta forma, conhecer com antecedência qual a probabilidade de ocorrência de extremos de temperaturas mínimas e máximas é valioso no que diz respeito ao planejamento das atividades sociais e econômicas em geral. O objetivo do presente trabalho é apresentar a metodologia desenvolvida para determinar as temperaturas mínimas e máximas à superfície, a partir de informações do histórico do ponto de grade das previsões por conjunto do CPTEC sobre o Brasil, e fazer uma avaliação preliminar dos resultados obtidos. Além disso, utilizar um método estatístico simples, baseado na remoção do viés das previsões do MCGA-CPTEC para corrigir e aumentar o índice de acerto das previsões.

\section{DADOS E METODOLOGIA}

\subsection{Determinação das Temperaturas Mínimas e Máximas a partir das Previsões do Modelo e Dados Observados}

Para o presente estudo foram utilizadas as saídas horárias do histórico em ponto de grade das previsões por conjunto do CPTEC, dos meses de junho e julho de 2006. Cada conjunto é formado por 15 membros com previsões de até 15 dias. A partir destes dados, foram determinadas as temperaturas mínimas e as máximas para os 15 dias de previsão para todos os membros e 
para a média dos mesmos. Para determinar estas temperaturas foi utilizado o critério adotado no Brasil, pelo qual a leitura da temperatura mínima é realizada às 12:00 UTC, ou seja, a mínima é identificada entre o período das 12:00 UTC de um dia às 12:00 UTC do dia seguinte, e a máxima das 00:00 UTC de um dia às 00:00 UTC do dia seguinte.

Para a análise dos resultados, foram geradas séries temporais das previsões de temperaturas mínimas e máximas para os prazos de previsão de 2, 5, 10 e 15 dias para os 15 membros, além da média do conjunto, para os meses de junho e julho de 2006 nos pontos de grade do modelo onde estão situadas as capitais dos estados brasileiros. Para verificação dos resultados foram utilizados dados diários observados de temperaturas mínimas e máximas das estações meteorológicas automáticas ou convencionais situadas nas capitais estudadas, fornecidos pelo grupo de previsão climática operacional do CPTEC.

\subsection{Correção das Previsões}

Em geral, os erros das previsões numéricas de tempo estão associados, principalmente a dois fatores: às incertezas na condição inicial e às deficiências na formulação física e dinâmica dos modelos (Reynolds et al. 1994). Neste trabalho, as incertezas da condição inicial estão sendo consideradas a partir da aplicação de perturbações nas condições iniciais, já as incertezas na dinâmica e na física do modelo foram desconsideradas durante as integrações. Neste sentido, corrigir as previsões a partir de técnicas estatísticas pode compensar, ao menos parcialmente, os erros das previsões devido a representação incompleta da dinâmica e dos processos físicos da atmosfera pelo modelo. Uma das deficiências dos modelos globais, rodados em baixa resolução espacial, como neste trabalho, é a representação da topografia, que certamente é bastante suavizada quando comparada à original (Bonatti et al. 2004). Esta suavização da topografia pode ter um efeito significativo sobre a previsão de temperaturas mínimas do modelo, devido à forte variação da temperatura, normalmente observada com a altura.

No intuito de melhorar as previsões de temperaturas mínimas e máximas, estas foram corrigidas a partir de um método estatístico baseado na remoção do erro médio (viés), estimado a partir das previsões mais recentes. Para a escolha de tal método, considerou-se o fato de que os modelos podem apresentar variações nas tendências do erro dependendo do período de previsão, e estas variações, que são de curto prazo, podem ser determinadas através do cálculo do erro médio das previsões mais recentes (Cardoso et. al., 2006). Correções do viés do modelo com base em previsões mais recentes foram desenvolvidas nos estudos de Eckel e Mass (2005), Grimit et al. (2006) e Silva Dias e Moreira (2006), sendo demonstrado que estas correções podem contribuir para melhorar a confiabilidade e a resolução das previsões por conjunto.

Segundo Silva Dias e Moreira (2006) um período de 15 dias é suficiente para otimizar a correção pelo viés médio. Tendo em vista estes resultados, foram consideradas as previsões dos 15 dias anteriores ao dia selecionado, para o cálculo do viés a ser removido.

\section{3 Índices Estatísticos}

A taxa de acerto das previsões foi avaliada objetivamente a partir do cálculo de três índices estatísticos: erro médio (viés), raiz quadrada do erro quadrático médio (RMS), coeficiente de correlação de anomalias (r) (Wilks, 1995). Estes índices foram calculados para as previsões com e sem correções, com a finalidade de avaliar se as correções contribuem significativamente para aumentar a qualidade das previsões.

Considere uma variável $\mathrm{X}$ com os sub-índices $\mathrm{M}$ e $\mathrm{O}$, indicando o valor simulado $\left(\mathrm{X}_{\mathrm{M}}\right)$ e o valor observado $\left(\mathrm{X}_{\mathrm{O}}\right)$, respectivamente. $\mathrm{O}$ erro médio para a variável $\mathrm{X}$ é dado por:

$$
\text { VIÉS }=\frac{1}{N} \sum_{i=1}^{N}\left(X_{M i}-X_{O i}\right)
$$

em que $\mathrm{N}$ indica o número total de observações.

A raiz quadrada do erro quadrático médio é calculada como:

$$
\operatorname{RMS}=\left(\frac{1}{N} \sum_{i=1}^{N}\left(X_{M i}-X_{O i}\right)^{2}\right)^{1 / 2}
$$

O coeficiente de correlação de anomalias é dado por:

$$
r=\frac{\sum_{i=1}^{N}\left(X_{M i}^{\prime}-\bar{X}_{M}^{\prime}\right)\left(X_{O i}^{\prime}-\bar{X}_{O}^{\prime}\right)}{\sqrt{\sum_{i=1}^{N}\left(X_{M i}^{\prime}-\bar{X}_{M}^{\prime}\right)^{2} \sum_{i=1}^{N}\left(X_{O_{i}}^{\prime}-\bar{X}_{O}^{\prime}\right)^{2}}}
$$

onde a barra superior indica a média no período, e $\mathrm{X}^{\prime}{ }_{\mathrm{M}}=\mathrm{X}_{\mathrm{M}}-\mathrm{C}$, e $\mathrm{X}^{\prime}{ }_{\mathrm{O}}=\mathrm{X}_{\mathrm{O}}-\mathrm{C}$ (onde $\mathrm{C}$ é o valor da climatologia para o dia avaliado).

Além disso, calculou-se o índice "outliers", que é a razão entre número de dias em que a observação esteve fora da "pluma" prevista pelos membros do conjunto e o número total de dias estudado. 


\section{RESULTADOS}

Para cada capital dos estados brasileiros, foram realizadas comparações das previsões das temperaturas mínimas e máximas com as observações para os prazos de 2, 5, 10 e 15 dias. A escolha destes prazos de previsão foi motivada pelo fato de que os erros das previsões são diferentes para cada prazo, por isso torna-se importante conhecer qual é o comportamento e com qual antecedência podemos obter informações úteis a partir destas previsões. Entretanto, a utilização de todos os prazos de previsão tornaria o trabalho demasiadamente longo, desta forma, considera-se que os resultados apresentados representam o comportamento geral das previsões. Já a avaliação por capitais tem a finalidade de produzir um panorama geral do desempenho das previsões sobre o Brasil, que apresenta características variadas especialmente durante o inverno, e também pelo fato de que boa parte da população brasileira encontra-se próxima destas localidades. A capital mais populosa de cada região geográfica foi selecionada para ser apresentada neste trabalho. Para as demais, embora tenham sido avaliadas, as figuras são omitidas.

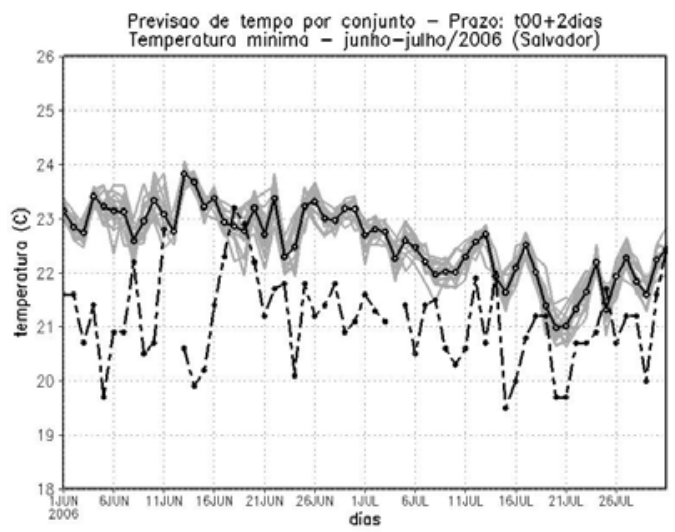

a)

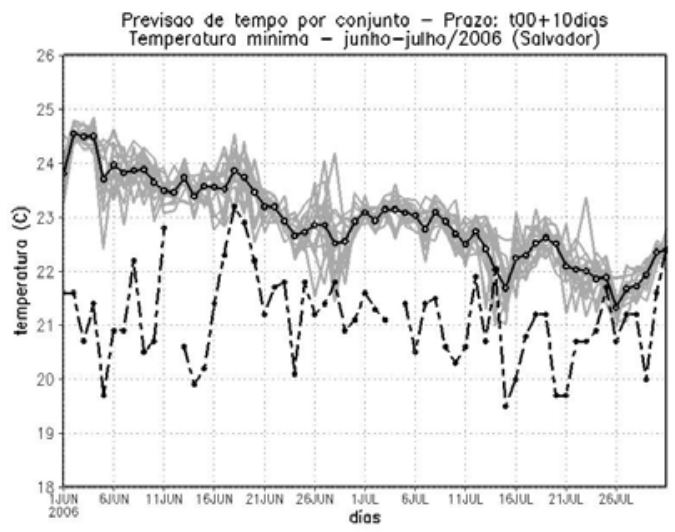

c)

\subsection{Temperatura Mínima}

A Figura 1 apresenta as séries temporais da temperatura mínima para todos os membros da previsão por conjunto (linhas cinza), o conjunto médio (linha preta contínua) e as observações (linha preta pontilhada) para Salvador (Bahia), para os meses de junho e julho de 2006. Em geral, o modelo apresenta temperaturas mais elevadas do que as observadas para todos os prazos de previsão, o que mostra claramente que o modelo possui um erro sistemático nas previsões de temperaturas mínimas para o período analisado. É possível notar ainda, que as temperaturas previstas estão mais próximas dos valores observados nos últimos 15 dias de julho.

Os resultados das demais capitais da região Nordeste são similares ao obtido em Salvador, com exceção de Aracaju, onde as temperaturas mínimas previstas estão bem próximas das observadas, sendo que na maioria dos dias a curva das temperaturas observadas caiu dentro da "pluma" de temperaturas previstas pelos membros do conjunto e relativamente próximo da curva da média do conjunto, que seria a previsão mais provável.

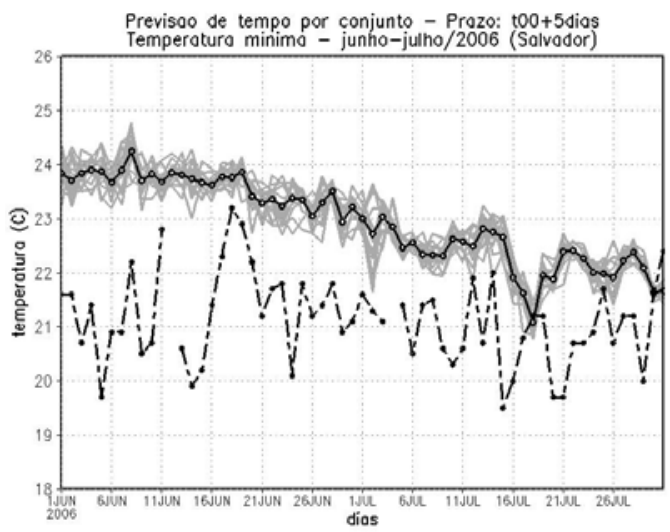

b)

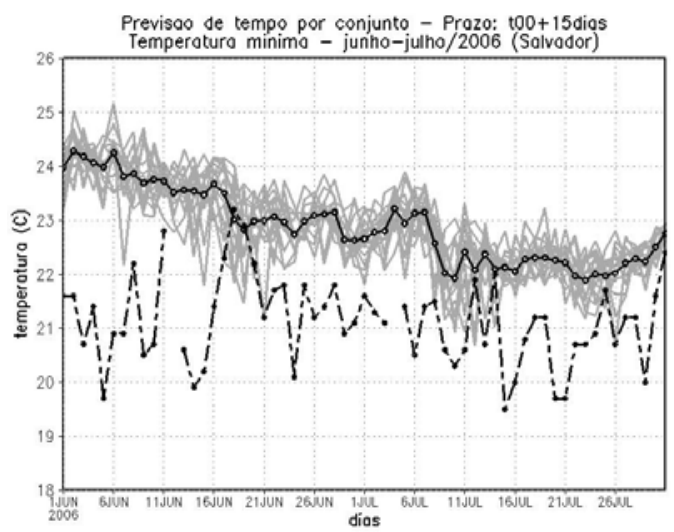

d)

Figura 1 - Série temporal das previsões de temperaturas mínimas para o período de 01 de junho a 31 de julho de 2006 para a cidade de Salvador. As linhas cinza representam os membros do conjunto e a linha preta contínua o conjunto médio, para os prazos de (a) 2 dias, (b) 5 dias, (c) 10 dias e (d) 15 dias. A linha preta pontilhada representa os valores observados. 


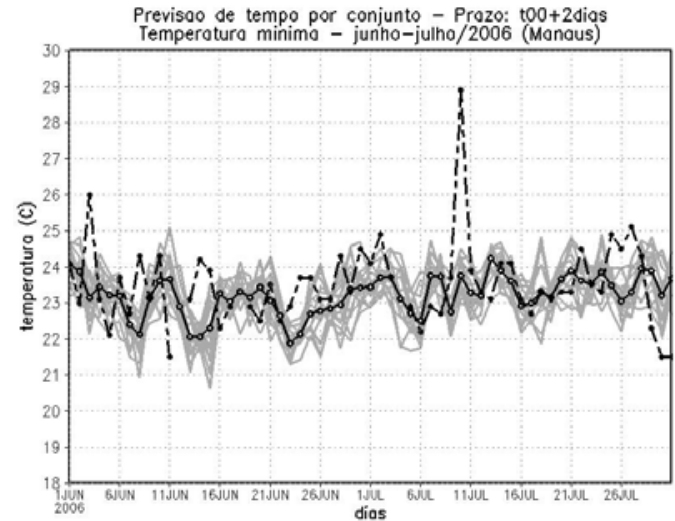

a)

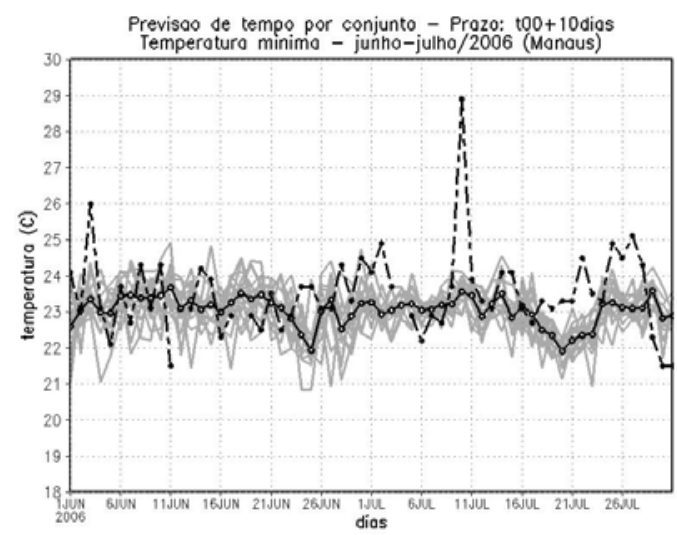

c)

Figura 2 - Idem a 1, mas para a cidade de Manaus.

Um resultado interessante a ser observado na Figura 1 é que o espalhamento dos membros não aumenta significativamente com o aumento do prazo de previsão, resultado que também foi obtido para as demais capitais nordestinas, exceto para Aracaju, onde é observado um espalhamento relativamente maior para os prazos mais longos. O baixo crescimento do espalhamento com o tempo nesta região está, em parte, associado à baixa variabilidade natural das temperaturas em climas tropicais. Além disso, sugere que as previsões não estão divergindo suficientemente nesta região.

A Figura 2 apresenta a série temporal das previsões de temperatura mínima para Manaus. Para todos os prazos $(2,5,10$ e 15 dias $)$ as temperaturas previstas pelo modelo para esta capital se aproximam bem das observadas. Notase claramente na Figura 2, que as temperaturas observadas (linha preta tracejada) estão próximas dos valores previstos pelo conjunto médio (linha preta contínua). Isto indica que o modelo atmosférico utilizado nestas simulações, apresenta um erro sistemático médio relativamente pequeno para a cidade de Manaus, o que é confirmado pelos valores baixos do viés para os prazos utilizados nesta avaliação: $-0,28,-0,40,-0,46$, $-0,70$. O índice "outliers" apresenta valores relativamente altos,

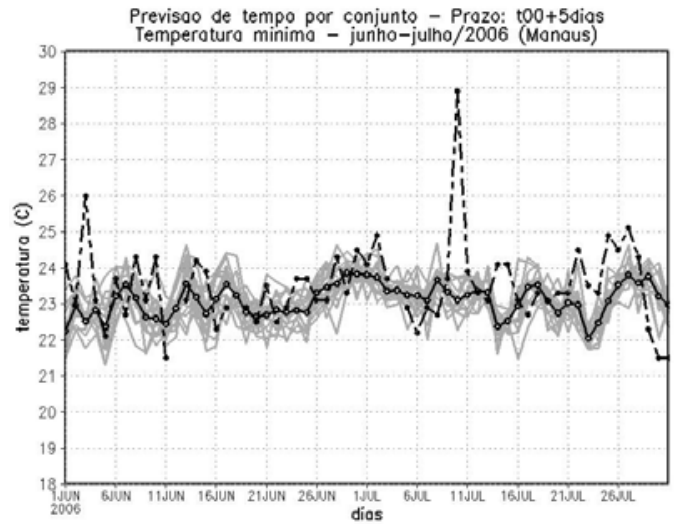

b)

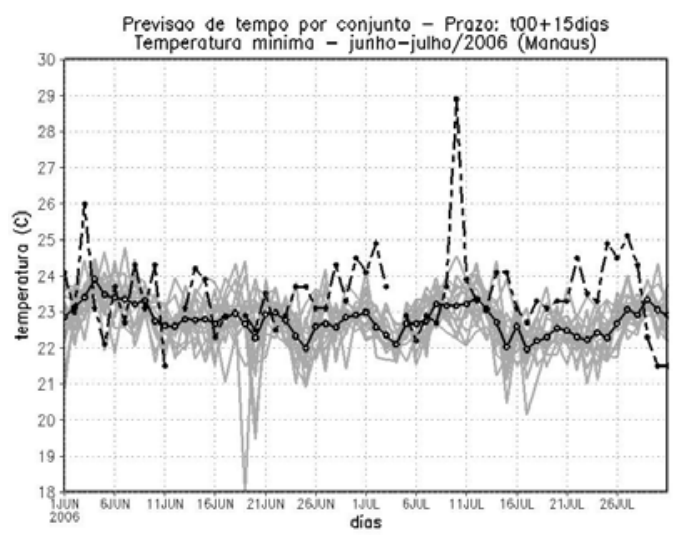

d)
$41,30 \%, 50,00 \%, 50,00 \%$ e $43,48 \%$ para os prazos de $2,5,10$ e 15 dias (Tabela 1), respectivamente.

O fato do erro sistemático do modelo para Manaus ser relativamente baixo, não é incoerente com os valores altos encontrados para os "outliers". Esta aparente incoerência pode ser explicada pelo fato que diferentes informações das previsões por conjunto estão sendo avaliadas por cada índice. Particularmente, os baixos valores do viés obtidos para o conjunto médio indicam que o modelo apresenta um erro sistemático relativamente pequeno para a cidade de Manaus quando comparado, por exemplo, ao erro sistemático encontrado para Salvador. Os "outliers" medem a calibração das previsões por conjunto, em termos da dispersão entre os membros. Valores elevados de "outliers" indicam que o sistema apresenta dispersão menor do que o desejado, uma vez que, em condições ideais, as previsões dos membros deveriam conter os valores observados, e o índice "outliers" deveria ser baixo. Ou seja, em sistemas com baixos erros sistemáticos não se pode afirmar que os "outliers" serão igualmente baixos. Embora, seja esperado que em sistemas com erro sistemático elevado haja um número grande de "outliers". Para uma interpretação correta das duas informações sendo avaliadas, é necessário levar em conta a variabilidade natural 
Tabela 1 - Desempenho das previsões de temperaturas mínimas do conjunto médio sem correção e corrigidas, para o período de 16 de junho a 31 de julho.

\begin{tabular}{|c|c|c|c|c|c|c|c|c|}
\hline 5 dias & 1,79 & 2,05 & $-0,05$ & 89,17 & $-0,35$ & 0,91 & $-0,10$ & 67,39 \\
\hline 10 dias & 1,80 & 2,03 & 0,02 & 86,97 & $-0,34$ & 0,86 & 0,19 & 56,52 \\
\hline 15 dias & 1,75 & 2,00 & $-0,04$ & 80,43 & $-0,29$ & 0,92 & $-0,03$ & 43,48 \\
\hline Manaus & viés & rms & $\mathbf{r}$ & outliers $(\%)$ & viés & rms & $\mathbf{r}$ & outliers(\%) \\
\hline 2 dias & $-0,28$ & 1,25 & 0,19 & 41,30 & 0,16 & 1,21 & 0,26 & 47,83 \\
\hline 5 dias & $-0,40$ & 1,27 & 0,15 & 50,00 & 0,07 & 1,24 & 0,14 & 39,13 \\
\hline 10 dias & $-0,46$ & 1,27 & 0,13 & 50,00 & $-0,05$ & 1,23 & 0,23 & 41,30 \\
\hline 15 dias & $-0,70$ & 1,40 & 0,07 & 43,48 & $-0,02$ & 1,24 & 0,19 & 34,78 \\
\hline Brasilia & viés & rms & $\mathbf{r}$ & outliers(\%) & viès & rms & $r$ & outliers(\%) \\
\hline 2 dias & 0,04 & 1,58 & 0,55 & 50,00 & $-0,34$ & 1,57 & 0,62 & 47,83 \\
\hline 5 dias & $-0,68$ & 2,19 & 0,42 & 52,17 & $-0,81$ & 2,04 & 0,56 & 50,00 \\
\hline 10 dias & $-0,42$ & 1,98 & 0,22 & 19,57 & $-0,11$ & 2,07 & 0,22 & 21,74 \\
\hline 15 dias & $-1,05$ & 2,11 & 0,00 & 17,39 & $-0,33$ & 1,98 & 0,00 & 17,39 \\
\hline São Paulo & viés & rms & $\mathbf{r}$ & outliers (\%) & viés & rms & $\mathbf{r}$ & outliers(\%) \\
\hline 2 dias & 3,07 & 3,27 & 0,40 & 95,65 & $-0,20$ & 1,15 & 0,82 & 78,26 \\
\hline 5 dias & 2,06 & 3,13 & $-0,03$ & 91,30 & $-0,31$ & 2,33 & $-0,02$ & 71,74 \\
\hline 10 dias & 1,43 & 2,93 & $-0,06$ & 60,87 & $-0,22$ & 2,48 & $-0,14$ & 67,39 \\
\hline 15 dias & 2,12 & 2,80 & 0,12 & 50,00 & $-0,02$ & 2,04 & 0,18 & 36,96 \\
\hline Curitiba & viés & rms & $\mathbf{r}$ & outliers $(\%)$ & viés & rms & $\mathbf{r}$ & outliers(\%) \\
\hline 2 dias & 2,98 & 3,55 & 0,46 & 97,83 & $-0,07$ & 1,97 & 0,76 & 80,43 \\
\hline 5 dias & 1,67 & 3,91 & 0,01 & 82,61 & $-0,37$ & 4,12 & $-0,23$ & 73,91 \\
\hline 10 dias & 0,85 & 3,17 & 0,11 & 63,04 & 0,12 & 3,60 & $-0,11$ & 50,00 \\
\hline 15 dias & 0,95 & 2,92 & 0,12 & 21,73 & 0,52 & 2,96 & 0,09 & 21,74 \\
\hline
\end{tabular}

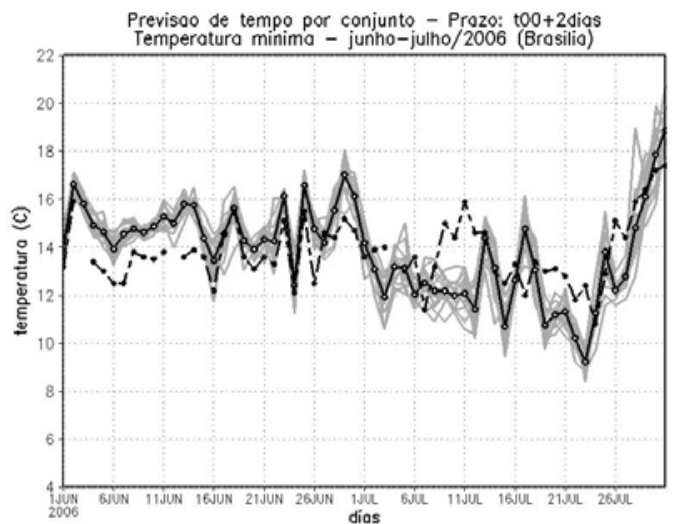

a)

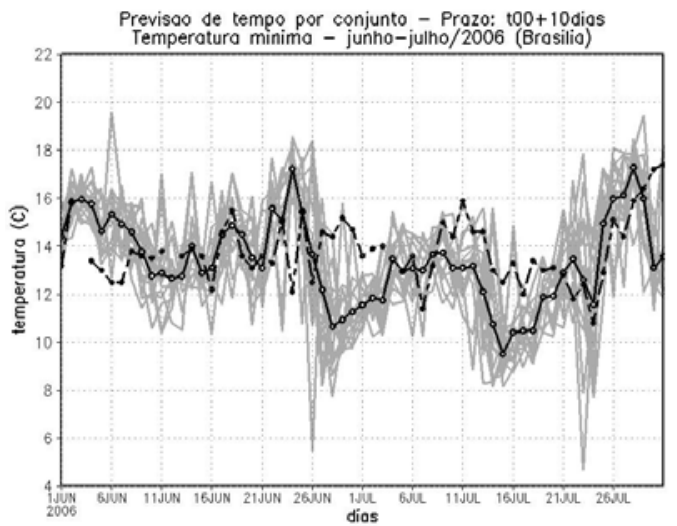

c)

Figura 3 - Idem a 1, mas para a cidade de Brasília.

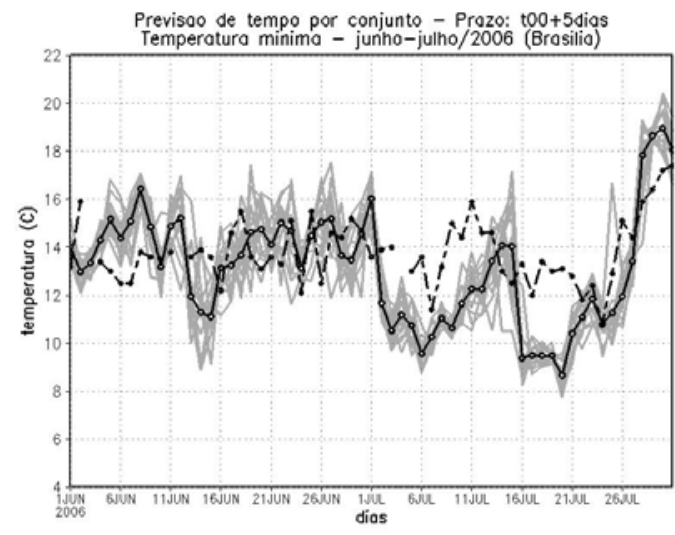

b)

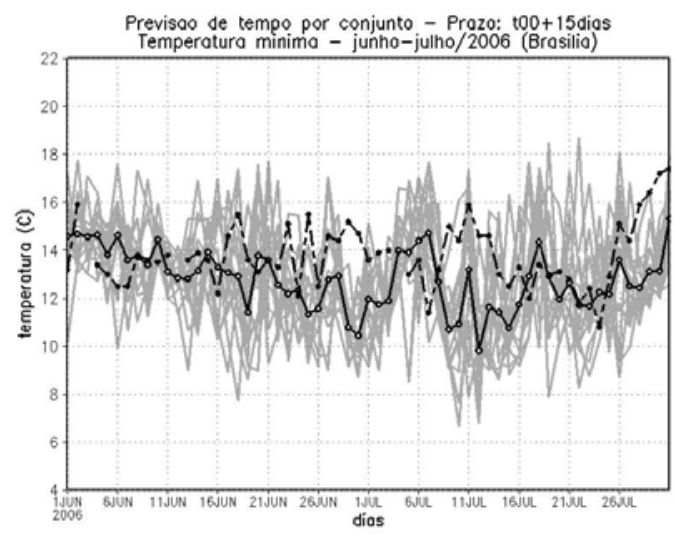

d) 
do campo em cada região, os erros sistemáticos do modelo, e o crescimento das perturbações em cada faixa de latitude.

Os resultados apresentados anteriormente sugerem que a dispersão dos membros do conjunto do CPTEC é menor do que o esperado para Manaus. Resultados semelhantes foram encontrados para outras capitais da região norte, como Boa Vista e Macapá. As localidades de Belém, Rio Branco e Porto Velho (Figuras não mostradas) apresentam um grande número de dias onde a temperatura observada ficou fora da "pluma" de temperaturas previstas pelos membros do conjunto, principalmente nos prazos de previsão mais curtos (2 e 5 dias), sendo os outliers para 2 dias de previsão $82,60 \%$ para Belém, 84,78\%.para Rio Branco e 97,83\% para Porto Velho.

Com relação ao espalhamento dos membros, nota-se que, assim como em Salvador, em Manaus não é observado aumento no espalhamento com o aumento do prazo de previsão.

Brasília, Figura 3, apresenta resultados bastante satisfatórios, na qual a previsão por conjunto capturou razoavelmente bem as temperaturas mínimas observadas. As tendências das temperaturas mínimas são bem representadas pelo conjunto, especialmente para o prazo de 2 dias (Figura

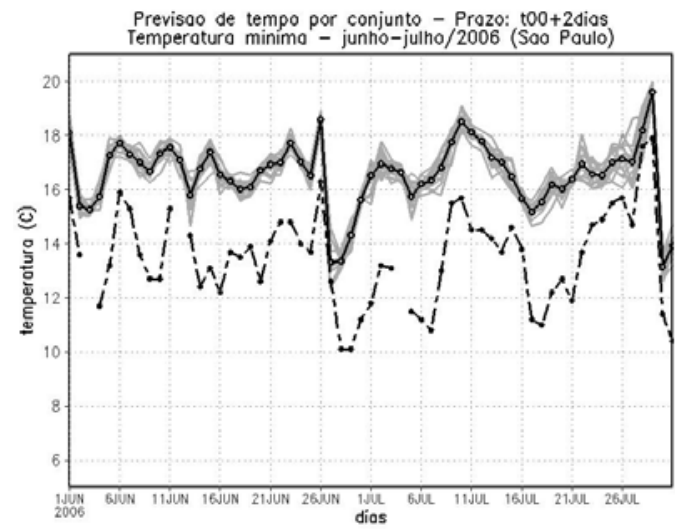

a)

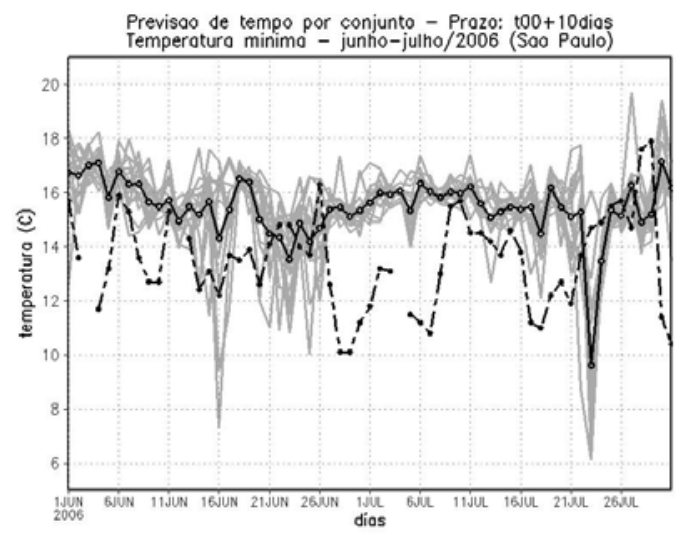

c)

Figura 4 - Idem a 1, mas para a cidade de São Paulo. 3a), como pode ser verificado pela valor de correlação $(0,55)$, indicado na Tabela 1. Para os prazos de previsão maiores (Figura 3c e d), apesar das tendências da temperatura não serem bem capturadas (correlações de 0,22 e 0,00, respectivamente, ver Tabela 1) as temperaturas observadas estiveram dentro da "pluma" dos membros em boa parte do período avaliado. Foram obtidos outliers relativamente baixos, $19,57 \%$ e 17,39\%, para 10 e 15 dias, respectivamente.

A Figura 4 apresenta a série temporal das temperaturas mínimas para os quatro prazos de previsão apresentados neste trabalho para a cidade de São Paulo. Nota-se claramente, que em São Paulo as temperaturas previstas apresentam-se acima das observadas, ou seja, o modelo apresenta um erro sistemático. $\mathrm{O}$ mesmo comportamento é observado no Rio de Janeiro e Vitória (Figuras não mostradas). Contudo, as tendências de aumento e diminuição são razoavelmente capturadas pelo modelo, principalmente para o prazo de 2 dias (correlação de anomalias de 0,40 para São Paulo). Para prazos maiores de previsão (10 e 15 dias), as tendências não são capturadas adequadamente (correlações de -0,06 e 0,12, respectivamente) e devido ao erro sistemático do modelo em prever temperaturas maiores do que

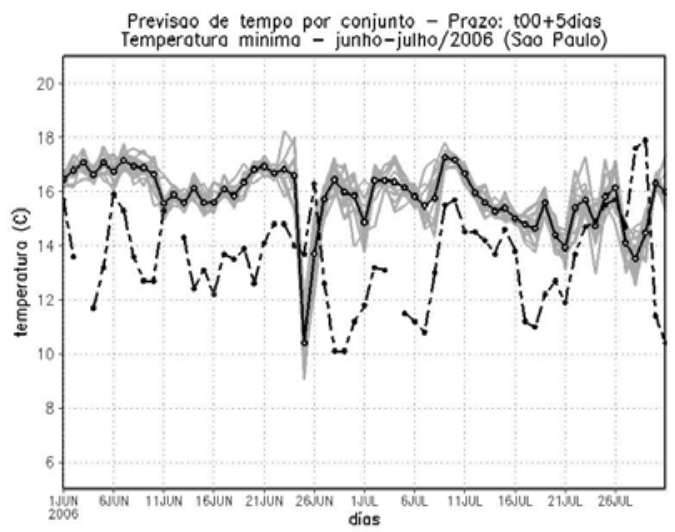

b)

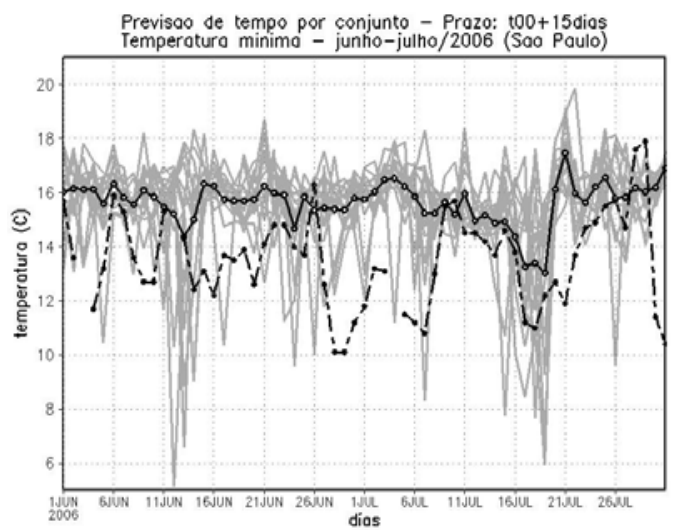

d) 


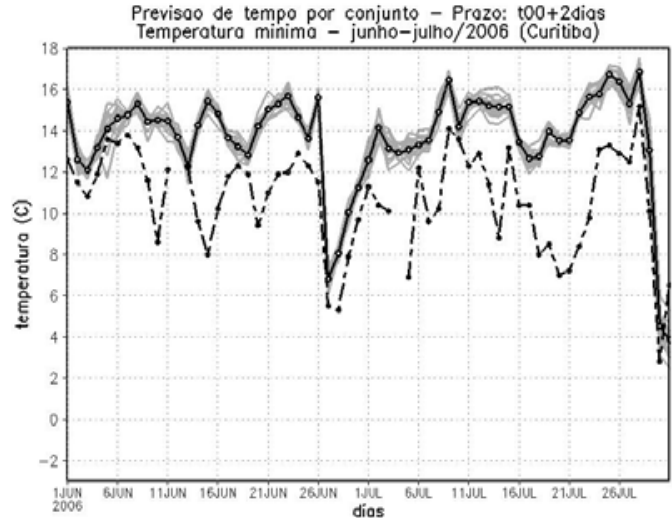

a)

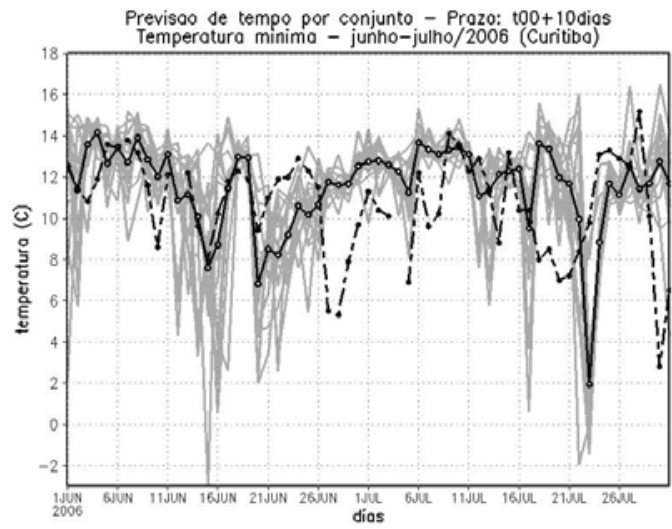

c)

Figura 5 - Idem a 1, mas para a cidade de Curitiba.

as observadas, em boa parte do período estudado as observações estão fora da "pluma" das temperaturas previstas pelos membros do conjunto (outliers de $60,90 \%$ e $50,00 \%$ para os prazos de 10 e 15 dias, respectivamente).

Já em Belo Horizonte (Figura não mostrada), ocorre um fato interessante, pois as temperaturas mínimas previstas estão abaixo da observada, ou seja, para esta localidade o modelo prevê temperaturas sistematicamente mais frias. Da mesma forma que para as outras capitais da região Sudeste, em Belo Horizonte, o modelo reproduz satisfatoriamente as variações diárias da temperatura nos prazos mais curtos de previsão, dando indícios das tendências observadas (correlações de 0,45 e 0,36, para os prazos de 2 e 5 dias, respectivamente).

Curitiba, Figura 5, é uma das capitais que apresenta melhores resultados, pois o modelo conseguiu capturar relativamente bem as variações nas temperaturas mínimas observadas, principalmente para o prazo de 2 dias (Figura 5a), com uma correlação de 0,46 . Com o aumento do prazo de previsão, há uma diminuição dos erros sistemáticos do modelo e as temperaturas previstas aproximam-se mais da observada. Para os prazos de 10 e 15 dias (Figuras $5 \mathrm{c}$ e $5 \mathrm{~d}$ ) as tendências de temperatura não são propriamente capturadas, mas a "pluma"

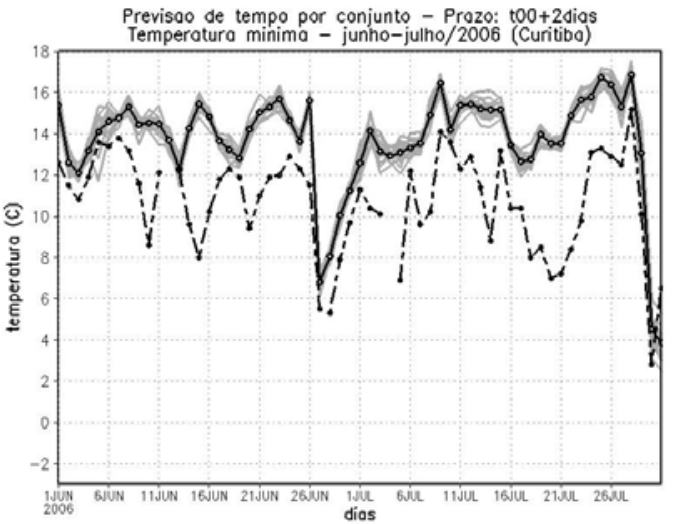

b)

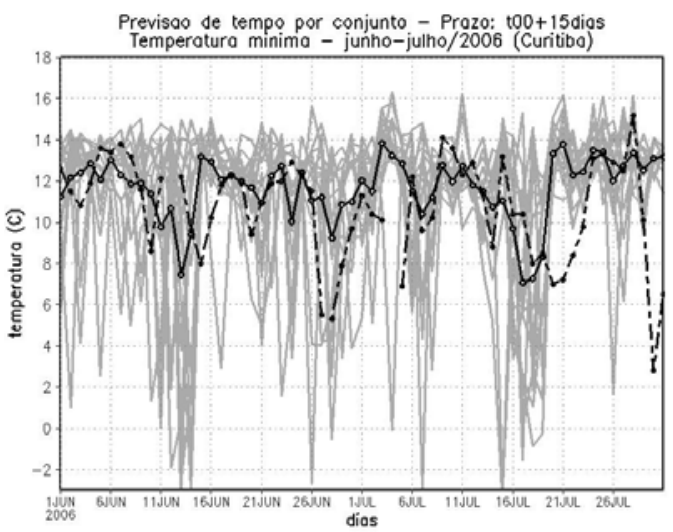

d)

de previsões, formada pelos membros do conjunto, consegue, em geral, indicar o intervalo no qual é esperado encontrar a observação (outiliers de $63,04 \%$ e $21,13 \%$, respectivamente). Pode-se notar ainda, a variabilidade diária do espalhamento, principalmente para o prazo de 10 dias (Figura 5c). Estas variações estão associadas com a confiabilidade da previsão. $\mathrm{Na}$ hipótese de um modelo não tendencioso, quando o espalhamento é baixo, a previsão é mais confiável do que nas situações em que o espalhamento é elevado.

É importante lembrar, que as temperaturas do modelo representam uma média em uma área de $100 \mathrm{~km}^{2}$, enquanto que a observação representa uma medida pontual. Mesmo assim, estes resultados sugerem que uma correção estatística das previsões, na qual o viés de previsões de temperaturas mais elevadas do modelo é removido, pode contribuir para aumentar o índice de acerto das previsões e torná-las mais realistas.

\subsection{Temperaturas mínimas corrigidas}

As Figuras de 6 a 10 apresentam as séries temporais das previsões de temperaturas mínimas corrigidas a partir do método apresentado no item 2.2, para o período de 16 de junho a 31 
a)

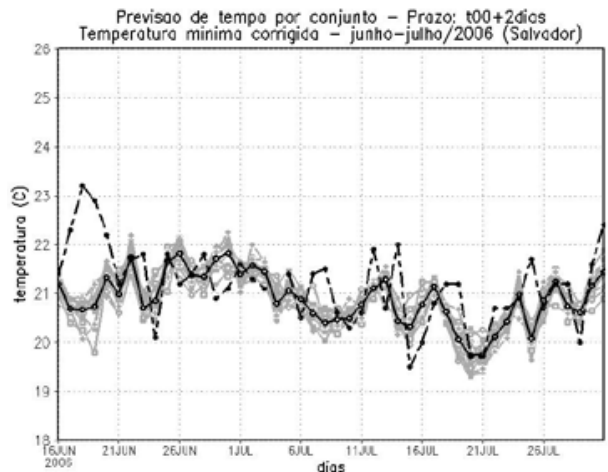

c)

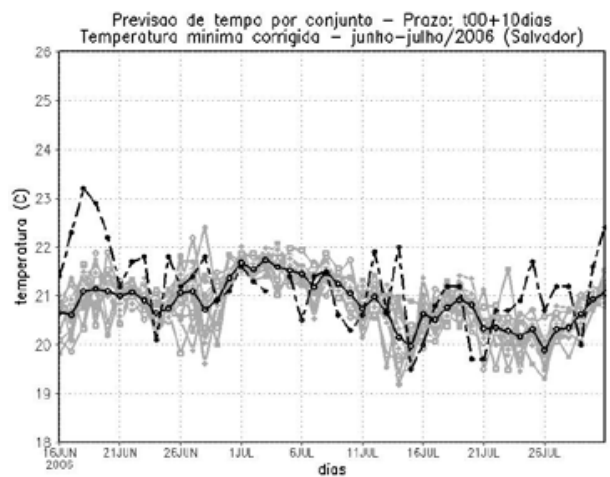

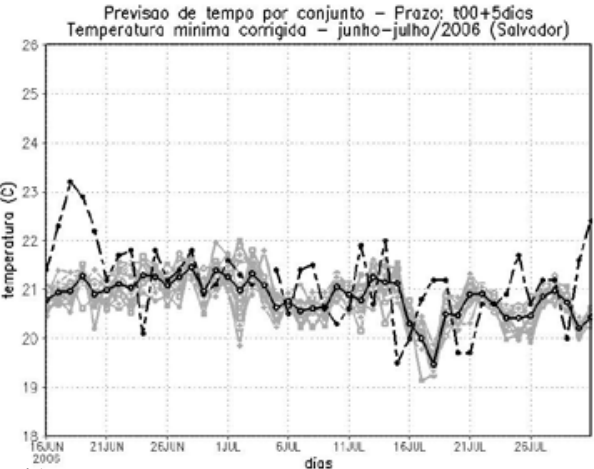

b)

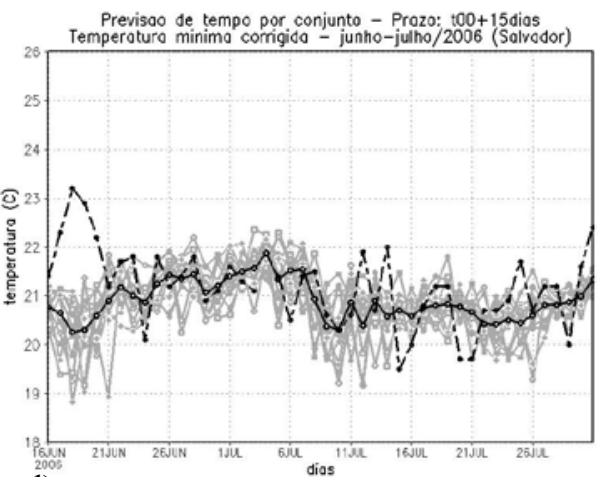

d)

Figura 6 - Série temporal das previsões de temperaturas mínimas corrigidas para o período de 16 de junho a 31 de julho de 2006 para a cidade de Salvador. As linhas cinza representam os membros do conjunto e a linha preta contínua o conjunto médio, para os prazos de (a) 2 dias, (b) 5 dias, (c) 10 dias e (d) 15 dias. A linha preta pontilhada representa os valores observados.

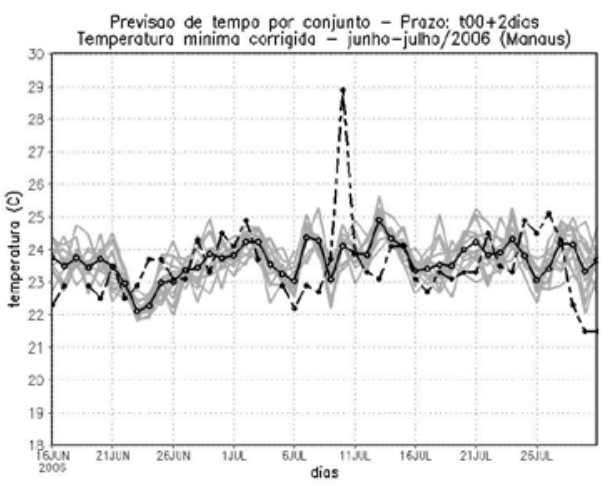

a)

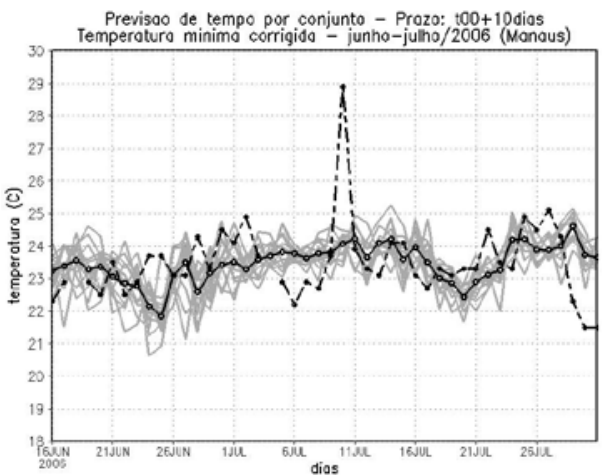

c)

Figura 7 - Idem a Figura 6, mas para Manaus.

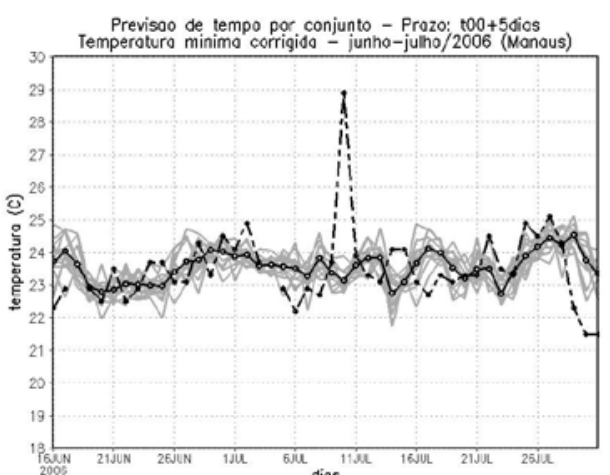

b)

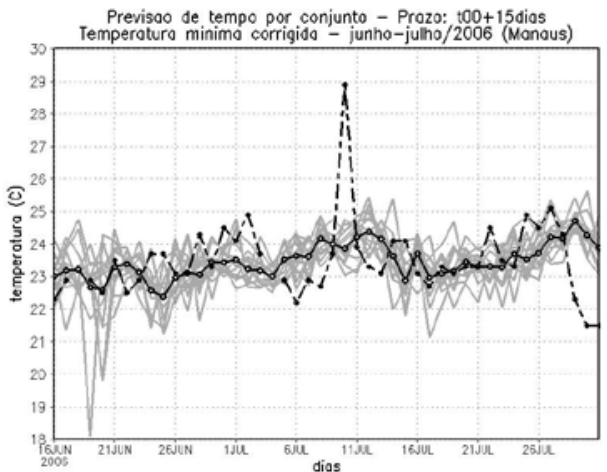

d) 
a)

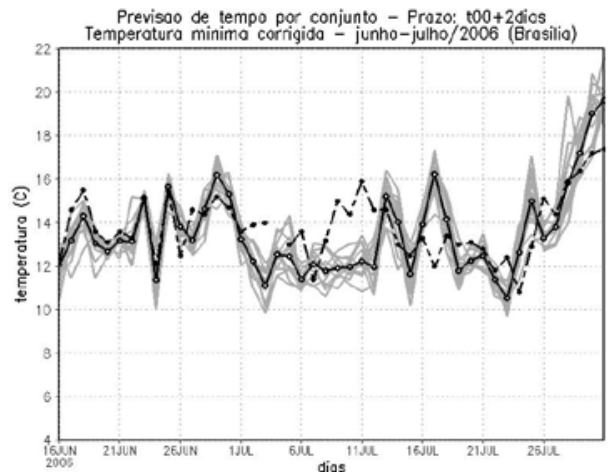

c)

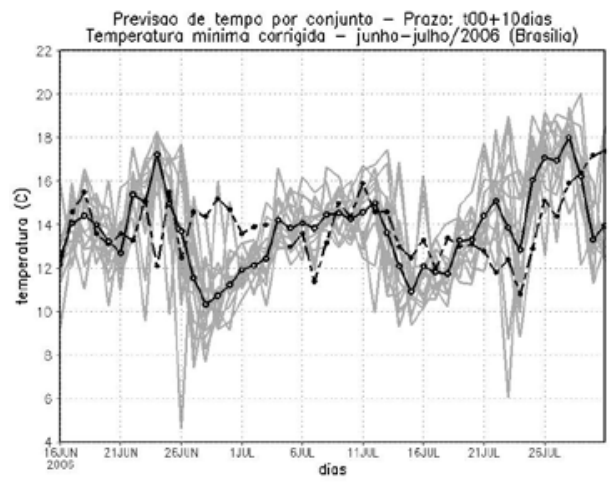

Figura 8 - Idem a Figura 6, mas para Brasília.

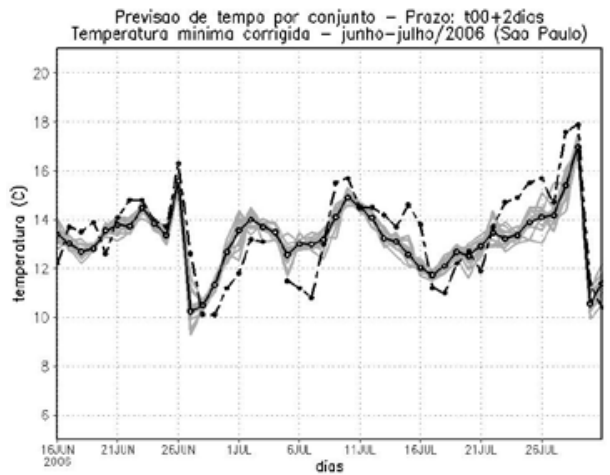

a)

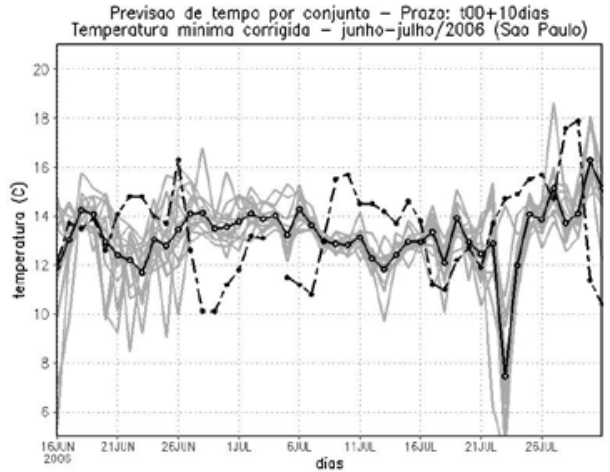

c)

Figura 9 - Idem a Figura 6, mas para São Paulo.

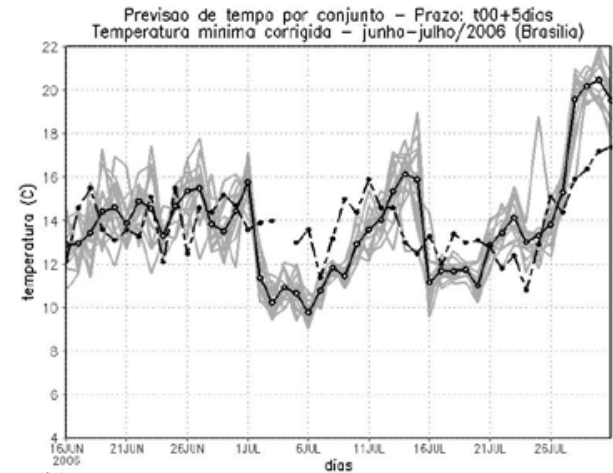

b)

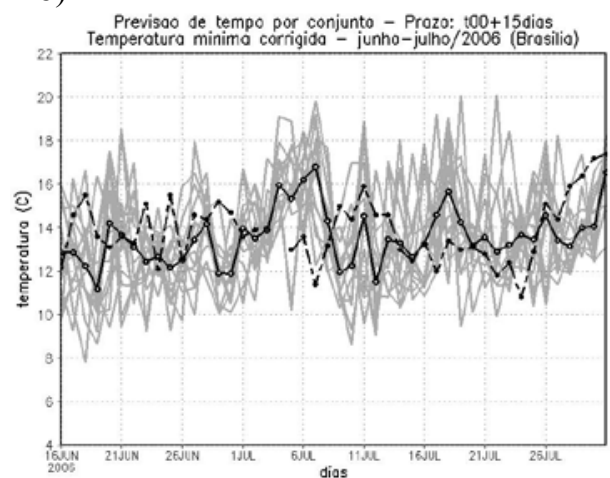

d)

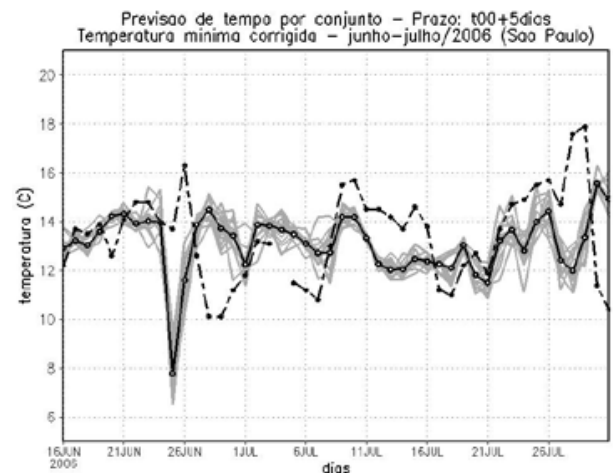

b)

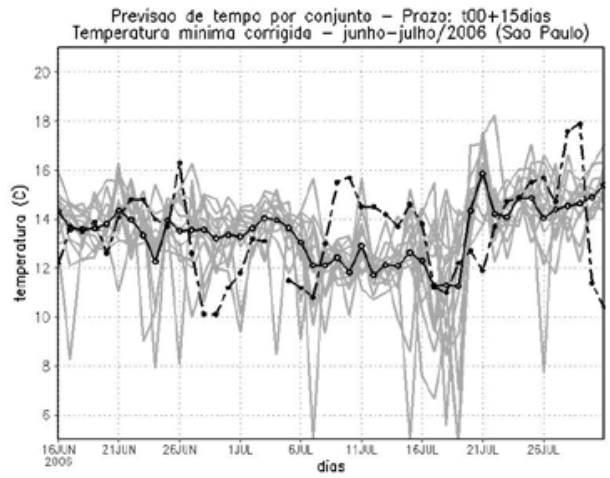

d) 


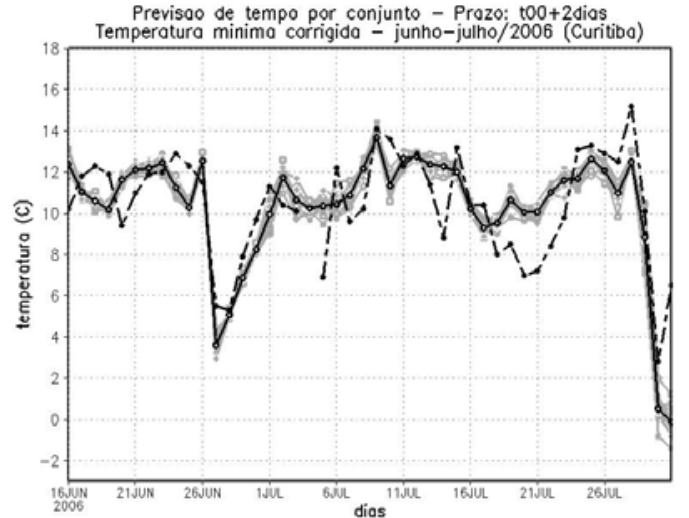

a)

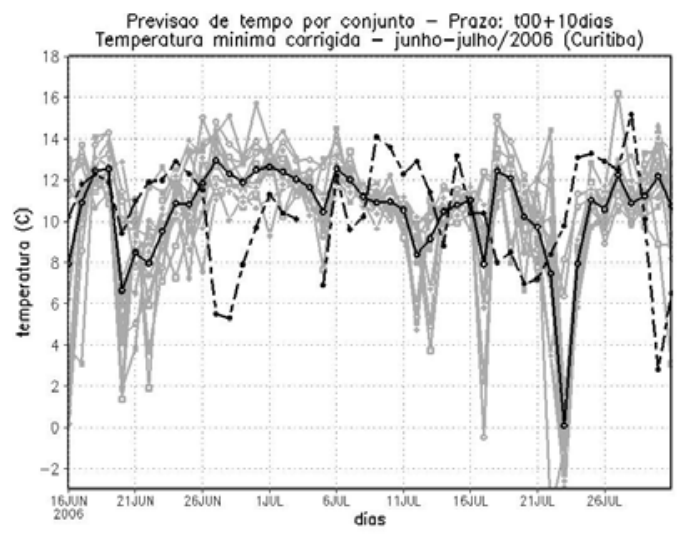

c)

Figura 10 - Idem a Figura 6, mas para Curitiba.

de julho. Os primeiros 15 dias de junho não são apresentados, pois foram utilizados para calcular os erros a serem removidos do dia 16. Fica evidente a diminuição da magnitude do erro das previsões para todos os prazos de previsão, assim como o aumento do número de casos em que a observação encontra-se dentro da "pluma" de temperaturas mínimas previstas pelos membros do conjunto.

Para confirmar quantitativamente os resultados discutidos anteriormente, na Tabela 1 são apresentados o erro médio (viés), a raiz quadrada do erro quadrático médio (rms) e o coeficiente de correlação de anomalias (r) para as previsões sem correção e para as previsões corrigidas. Todos os índices estatísticos são calculados considerando a série temporal da média do conjunto e as observações. De modo geral, nota-se uma redução significativa tanto do erro médio (viés) como do rms após a aplicação do método de correção, especialmente em Salvador e São Paulo. Observa-se ainda um aumento considerável nas correlações de anomalias entre as previsões e as observações. Para o prazo de 2 dias, houve um aumento nas correlações de anomalias em todas as capitais, chegando a 0,82 em São Paulo (Tabela 1). Em alguns casos (Salvador para 5 dias e São Paulo para 10 dias de previsão), em que havia correlação negativa antes

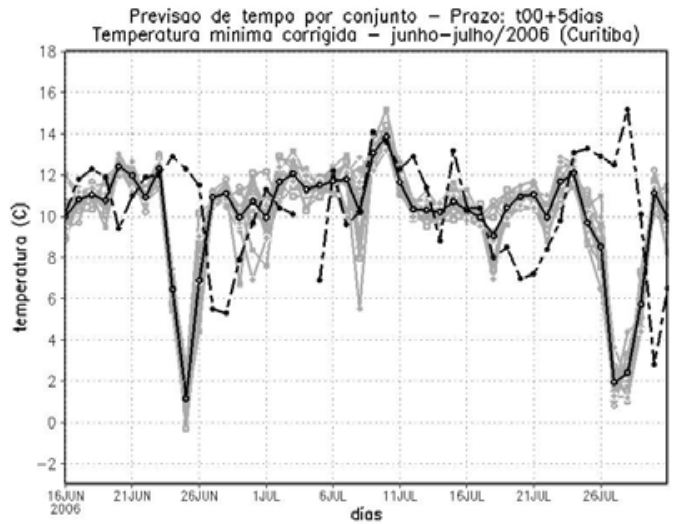

b)

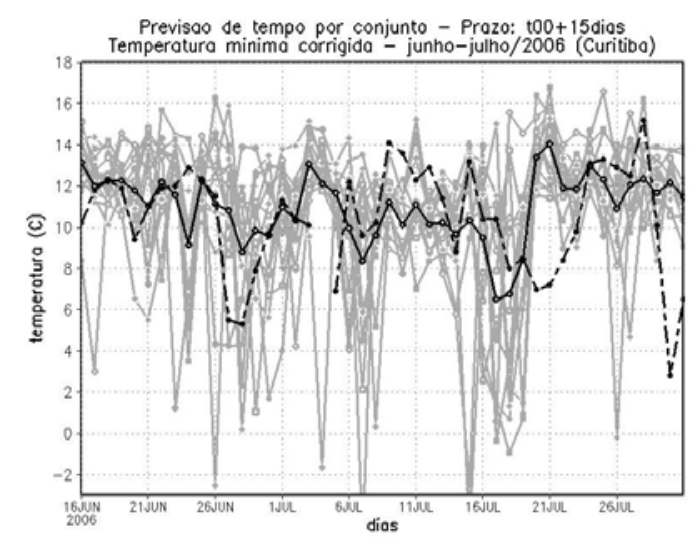

d)

da aplicação da correção, pode-se observar que as correlações aumentaram negativamente, indicando que as correções não ajudaram a identificar o sinal das anomalias de temperatura no período, entretanto, a diminuição do viés e do rms mostra que o erro sistemático de previsões de temperaturas mais elevadas do que as observadas é reduzido.

\subsection{Temperatura Máxima}

O mesmo procedimento adotado para obter as previsões de temperaturas mínimas foi utilizado para as temperaturas máximas. A Figura 11 apresenta as séries temporais da temperatura máxima para todos os membros da previsão por conjunto (linhas cinza), o conjunto médio (linha preta contínua) e as observações (linha preta pontilhada) para Salvador (Bahia), para os meses de junho e julho de 2006. Nota-se claramente, que as previsões apresentam um erro sistemático nas temperaturas máximas, assim como observado nas mínimas, porém as máximas previstas pelos membros do conjunto estão abaixo dos valores observados, em todos os prazos de previsão, exceto em alguns dias isolados, onde houve queda acentuada da temperatura observada (Figura 11). Ressalta-se que as 


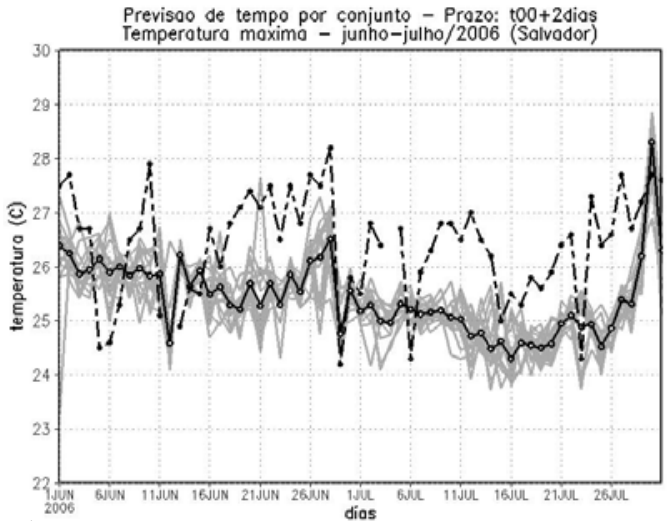

a)

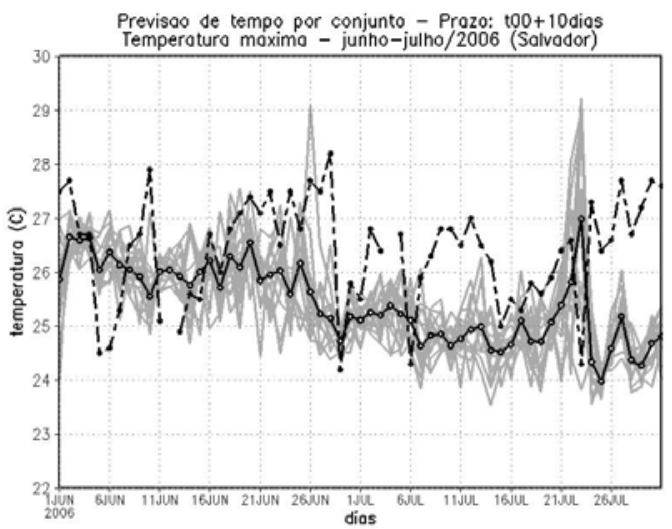

c)

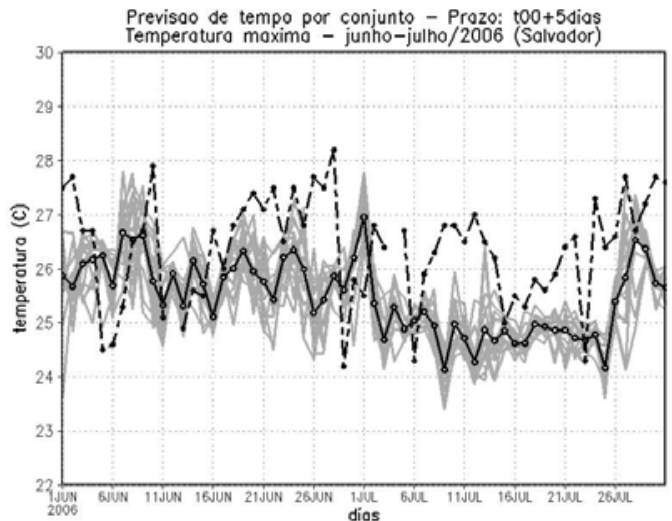

b)

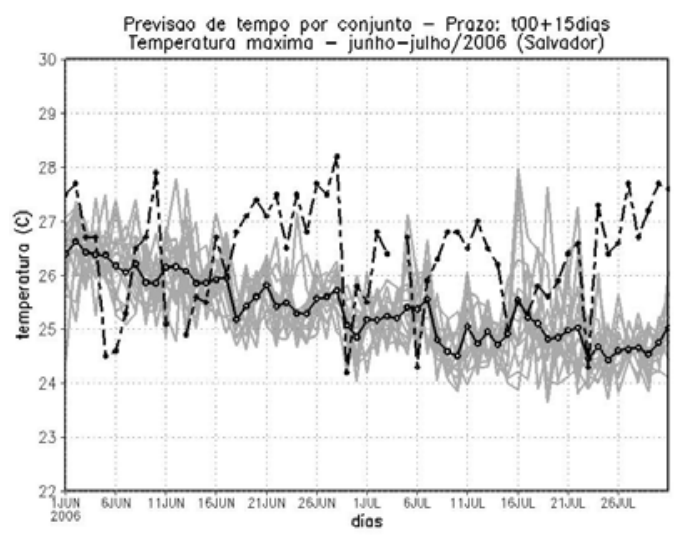

d)

Figura 11 - Série temporal das previsões de temperaturas máximas para o período de 01 de junho a 31 de julho de 2006 para a cidade de Salvador. As linhas cinza representam os membros do conjunto e a linha preta contínua o conjunto médio, para os prazos de (a) 2 dias, (b) 5 dias, (c) 10 dias e (d) 15 dias. A linha preta pontilhada representa os valores observados.

temperaturas mínimas previstas nesta localidade (Figura 1) mostraram-se mais quentes que o observado. Estes resultados sugerem que o modelo apresenta deficiência em reproduzir o ciclo diurno de temperatura, uma vez que as mínimas estão acima e as máximas abaixo dos valores observados (menor amplitude térmica).

Teresina (figura não mostrada) apresentou resultados diferentes das demais capitais da região nordeste, com temperaturas previstas muito próximas às observadas, estando a curva de máximas observada dentro da "pluma" de temperaturas previstas pelos membros do conjunto, com algumas discrepâncias em poucos dias, para todos os prazos de previsão (outliers de $41,30 \%, 32,60 \%, 50,00 \%$ e $56,52 \%$ para 2, 5, 10 e 15 dias, respectivamente).

A Figura 12 apresenta a série temporal de temperaturas máximas da previsão por conjunto e observada para Manaus. Esta capital também apresenta temperaturas máximas previstas abaixo da observada. Nota-se que as variações da temperatura não foram bem capturadas pelo conjunto de previsões, o que é comprovado pelas baixas correlações de anomalias obtidas nesta localidade (Tabela 2). No entanto, próximo ao final de julho (Figura 12) a "pluma" prevista pelos membros do conjunto aproxima-se da curva observada. Observa-se ainda um aumento progressivo do espalhamento com o aumento do prazo de previsão.

Brasília, Figura 13, apresenta temperaturas previstas mais próximas das observadas, onde tanto as tendências quanto a intensidade foram reproduzidas com coerência (correlação de anomalias de 0,84 e viés de $-0,01$ para o prazo de 2 dias de previsão (Tabela 2)). As demais capitais da região centro-oeste apresentam algumas discrepâncias em relação aos valores das temperaturas previstas e observadas. Estas diferenças diminuem gradativamente com o aumento do prazo de previsão, entretanto, para prazos maiores o nível de incerteza também aumenta. Vale ressaltar que, assim como visto na Figura 13, para estas localidades as tendências de aumento e diminuição das temperaturas também foram capturadas, com correlações de 0,36, 0,48 e 0,36 em Cuiabá, Campo Grande e Goiânia, respectivamente, para o prazo de 2 dias se previsão.

A Figura 14 apresenta a série temporal das temperaturas máximas para São Paulo. Mais uma vez o modelo apresenta temperaturas máximas abaixo da observada, porém simula 


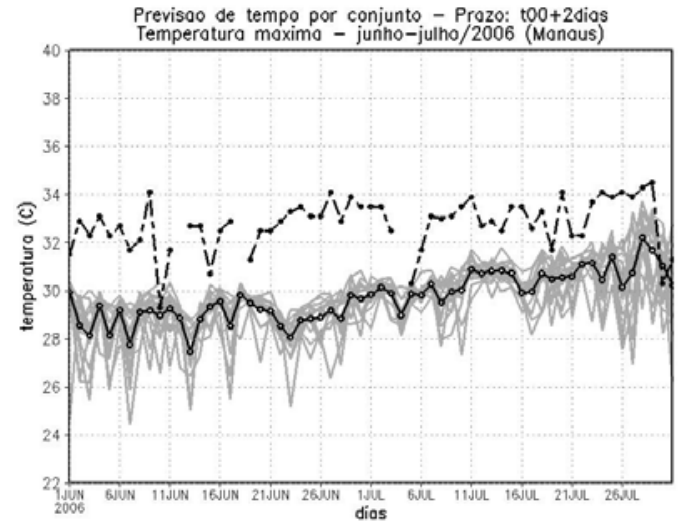

a)

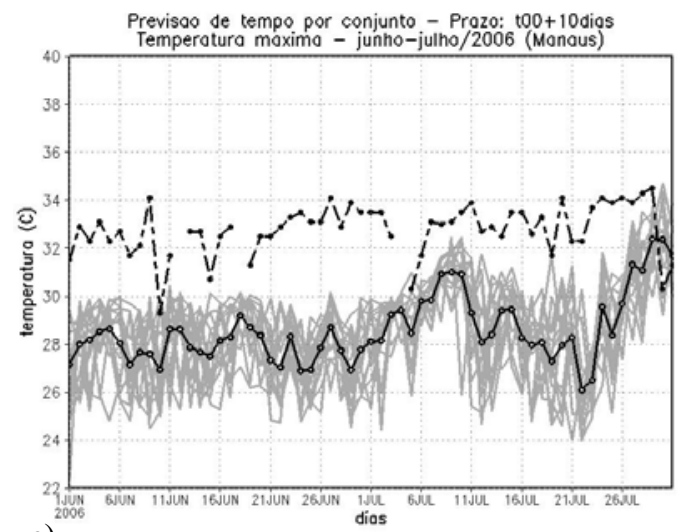

c)

Figura 12 - Idem a Figura 11, mas para Manaus.

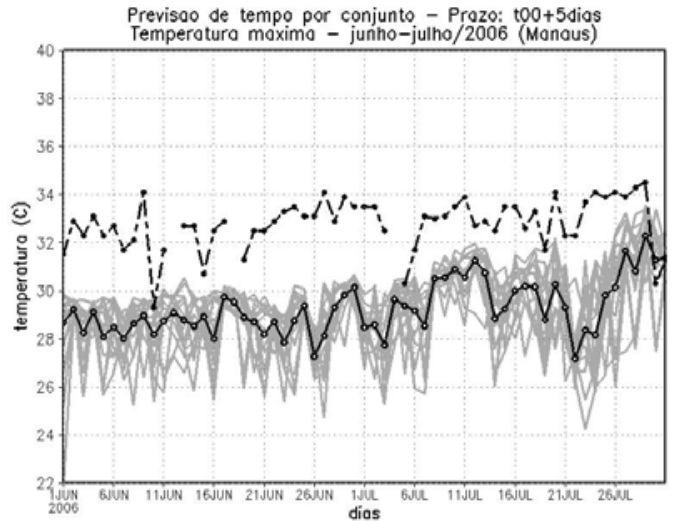

b)

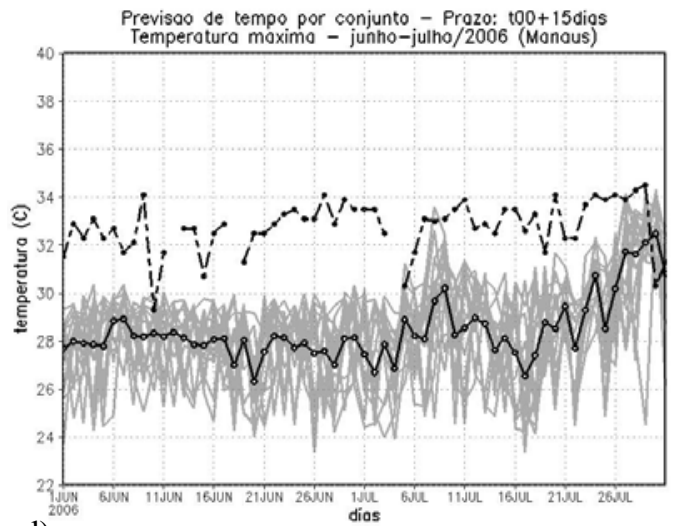

d)

Tabela 2 - Desempenho das previsões de temperatura máxima do conjunto médio sem correção e corrigidas, para o período de 16 de junho a 31 de julho.

\begin{tabular}{|c|c|c|c|c|}
\hline \multirow[b]{2}{*}{ Salvador } & \multicolumn{2}{|c|}{ Sem Corr eção } & \multicolumn{2}{|c|}{ Com Correção } \\
\hline & viés rms $r$ & outliers(\%) & ) viés rms $r$ & outliers(\%) \\
\hline 2 dias & $-0,951,36 \quad 0,24$ & 84,78 & $-0,220,940,40$ & 45,65 \\
\hline 5 dias & $-0,911,450,04$ & 84,78 & $-0,261,120,02$ & 65,22 \\
\hline 10 dias & $-0,901,58-0,11$ & 67,39 & $-0,381,21-0,25$ & 43,48 \\
\hline 15 dias & $-1,041,57-0,12$ & 65,22 & $-0,411,14-0,15$ & 50,00 \\
\hline Manaus & viés rms $\quad r$ & outliers(\%) & ) viés rms $r$ & outliers(\%) \\
\hline 2 dias & $-3,033,28 \quad 0,05$ & 93,48 & $0,191,190,01$ & 39,13 \\
\hline 5 dias & $-3,513,770,02$ & 93,48 & $0,121,560,05$ & 19,56 \\
\hline 10 dias & $-4,224,54 \quad 0,02$ & 93,48 & $0,222,03-0,06$ & 28,26 \\
\hline 15 dias & $-4,284,57-0,01$ & 91,30 & $0,251,750,02$ & 8,70 \\
\hline Brasília & viés rms $r$ & outliers(\%) & ) viés rms $r$ & outliers(\%) \\
\hline 2 dias & $-0,011,140,84$ & 63,04 & $0,08 \quad 1,310,80$ & 65,22 \\
\hline 5 dias & $0,081,67 \quad 0,42$ & 69,57 & $-0,011,850,59$ & 69,57 \\
\hline 10 dias & $-0,282,070,06$ & 63,04 & $-0,342,400,19$ & 63,04 \\
\hline 15 dias & $-0,212,04 \quad 0,24$ & 43,48 & $-0,402,370,12$ & 47,83 \\
\hline São Pau & viés rms $r$ & outliers(\%) & ) viés rms $r$ & outliers(\%) \\
\hline 2 dias & $-1,372,500,78$ & 84,78 & $0,102,410,83$ & 73,91 \\
\hline 5 dias & $-2,434,480,19$ & 84,78 & $-0,254,260,17$ & 80,43 \\
\hline 10 dias & $-3,055,54-0,34$ & 71,74 & $-0,255,44-0,52$ & 63,04 \\
\hline 15 dias & $-2,294,310,08$ & 54,35 & $0,294,300,14$ & 28,26 \\
\hline Curitiba & viés rms $r$ & outliers(\%) & ) viés rms $r$ & outliers(\%) \\
\hline 2 dias & $-2,243,00 \quad 0,74$ & 89,13 & $0,102,160,87$ & 69,57 \\
\hline 5 dias & $-3,555,550,11$ & 82,61 & $-0,474,580,01$ & 78,26 \\
\hline 10 dias & $-4,056,43-0,32$ & 76,09 & $-0,175,73-0,57$ & 58,70 \\
\hline 15 dias & $-3,535,310,001$ & 60,87 & $0,474,48 \quad 0,07$ & 32,61 \\
\hline
\end{tabular}




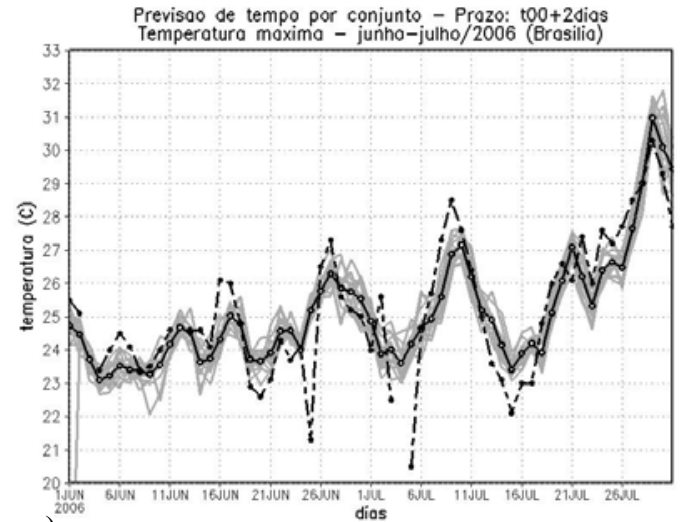

a)

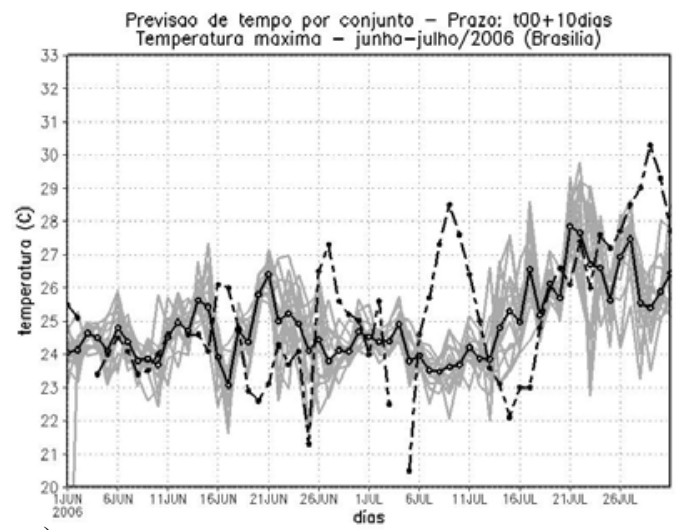

c)

Figura 13 - Idem a Figura 11, mas para Brasília.

relativamente bem as variações diárias da temperatura no curto prazo (2 dias), com correlação de 0,78 (Tabela 2). Para os prazos de previsão maiores, as tendências não são capturadas corretamente (correlação negativa), além disso, devido ao erro sistemático do modelo em prever temperaturas máximas inferiores às observadas, a pluma de previsões não consegue capturar os valores observados. A aplicação de uma correção estatística nestas previsões pode ajudar a corrigir esta deficiência.

A Figura 15 apresenta a série temporal das temperaturas máximas para Curitiba. Assim como nas demais Regiões, as previsões do conjunto indicam temperaturas máximas menores do que as observadas para a esta capital e para as demais capitais da região Sul. Para o prazo de 2 dias de previsão, a correlação entre as anomalias das temperaturas previstas e observadas é de 0,74 (Tabela 2), indicando que as tendências de aumento e diminuição foram capturadas pelo modelo para este prazo. Para os demais prazos, o número de dias em que as temperaturas observadas caem dentro ou muito próximo da "pluma" de temperaturas previstas aumenta com o aumento do prazo de previsão, com os outliers passando de $89,13 \%$ (2 dias) para $60,87 \%$ (15dias). Um esperado aumento do espalhamento das

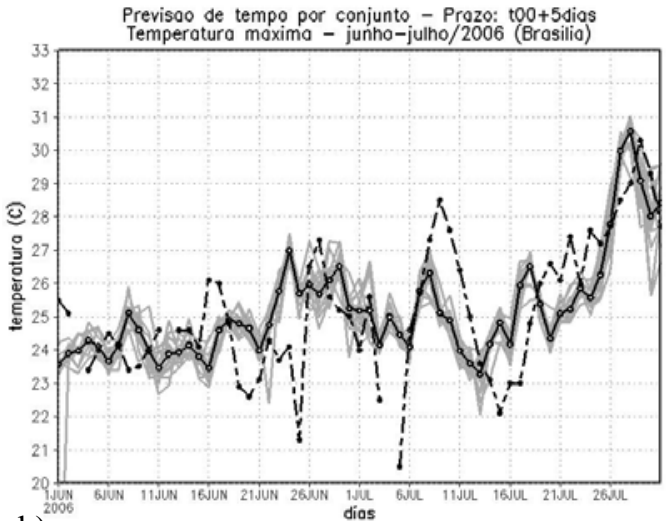

b)

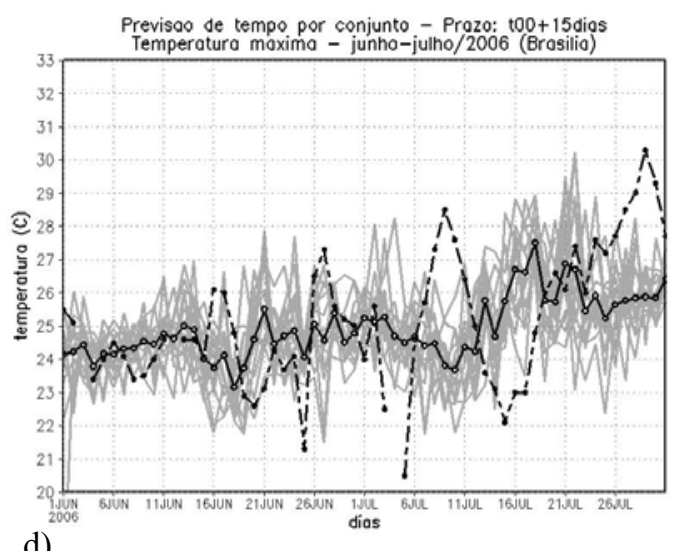

d)

previsões também é verificado com o aumento do prazo de previsão.

Destes resultados, pode-se concluir que o modelo apresenta um erro sistemático negativo em praticamente todas as capitais dos estados brasileiros (Tabela 2). Ressalta-se que os membros do conjunto apresentaram temperaturas mínimas acima das observadas (Tabela 1), sugerindo que o modelo apresenta certa deficiência em reproduzir o ciclo diurno de temperatura da atmosfera sobre o continente, ou seja, a amplitude térmica diária é subestimada pelo modelo.

\subsection{Temperaturas máximas corrigidas}

O mesmo método estatístico de correção aplicado para corrigir as previsões de temperaturas mínimas foi aplicado às previsões das temperaturas máximas. As Figuras 16 a 20 apresentam as séries temporais de temperaturas máximas previstas pelos membros do conjunto e observações para o período de 16 de junho a 31 de julho de 2006, para as capitais mais populosas das cinco regiões brasileiras. É possível notar que houve uma melhoria nos resultados, independentemente da região, o que pode ser confirmado na Tabela 2. Em praticamente 
a)
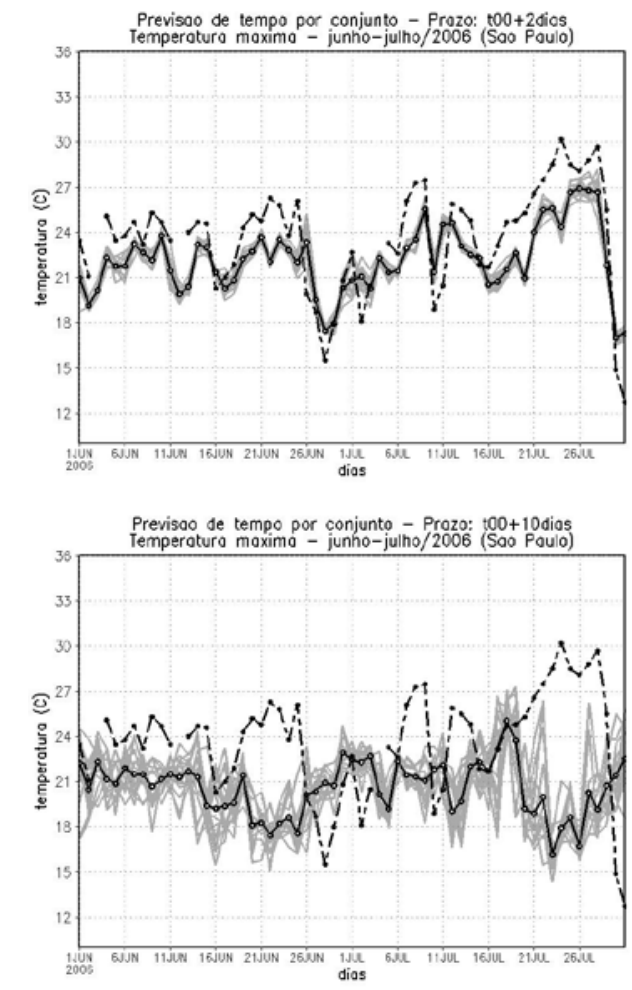

c)

Figura 14 - Idem a Figura 11, mas para São Paulo.

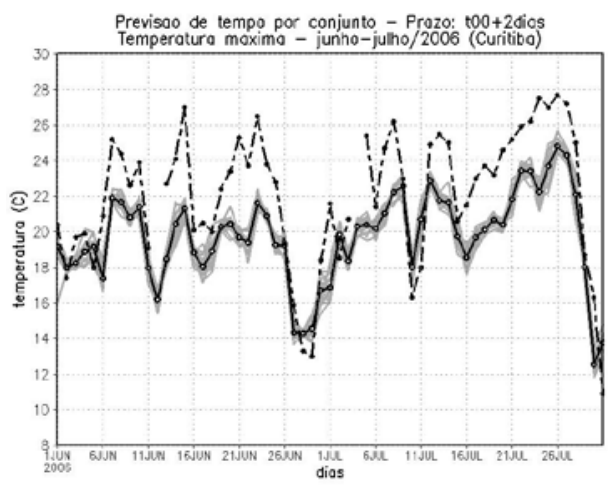

a)

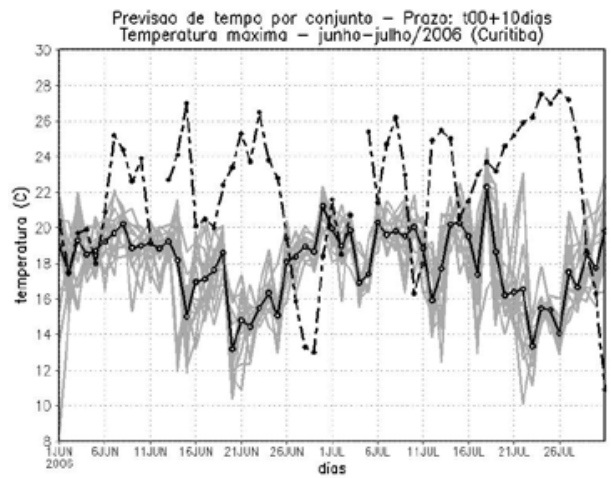

c)

Figura 15 - Idem a Figura 11, mas para Curitiba.

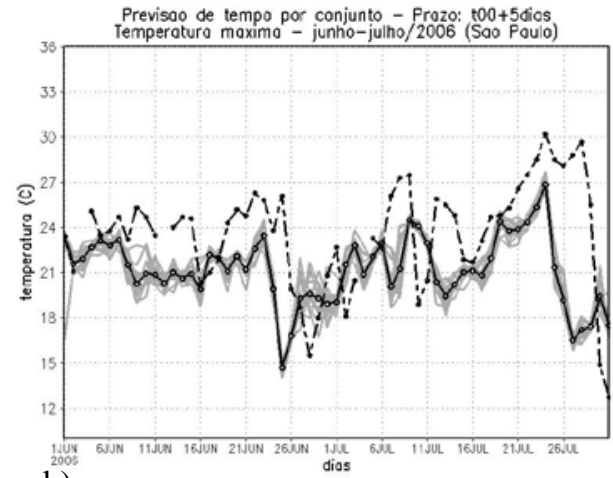

b)

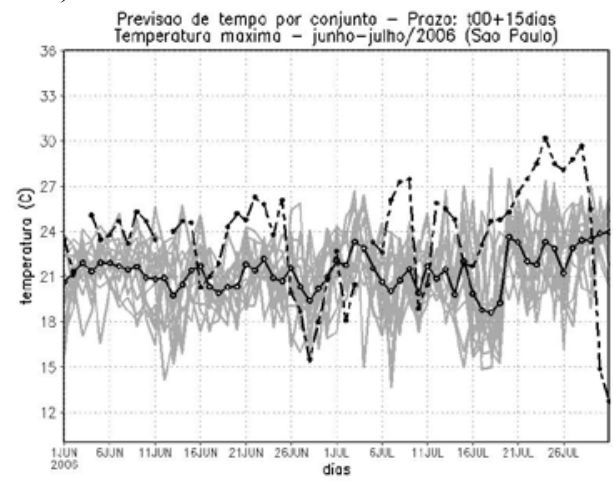

d)

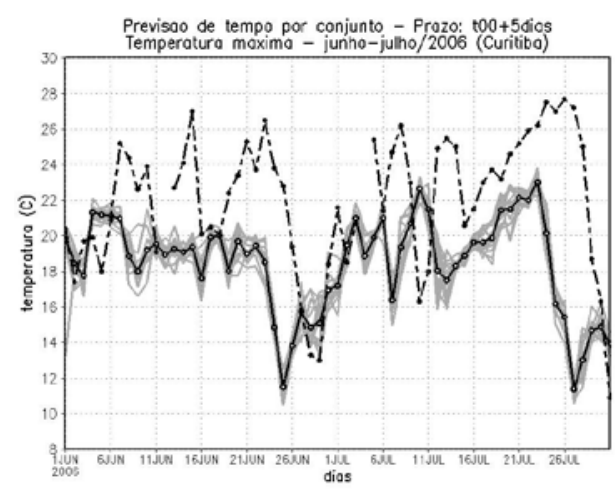

b)

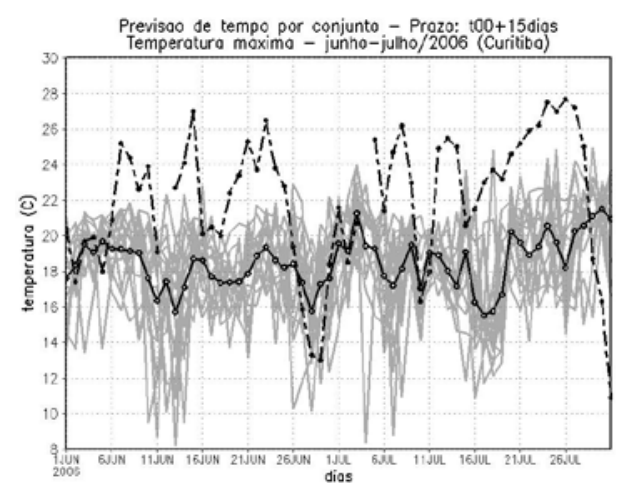

d) 


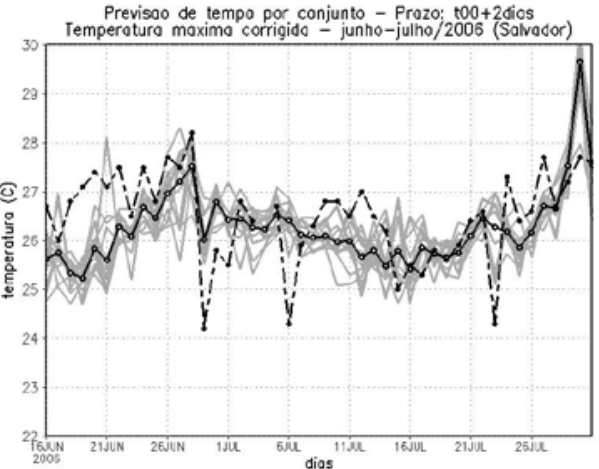

a)

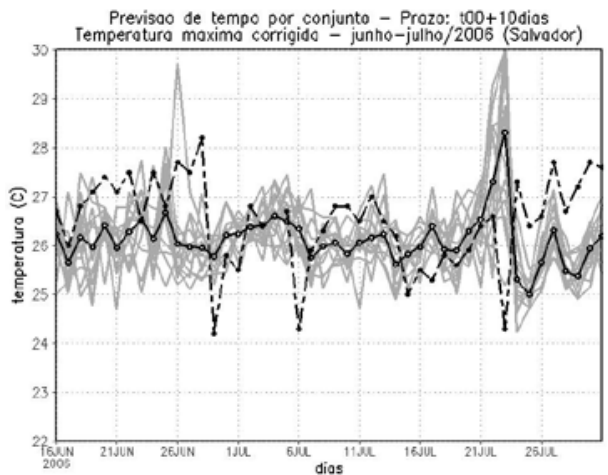

c)

Figura 16 - Série temporal das previsões de temperaturas máximas corrigidas para o período de 16 de junho a 31 de julho de 2006 para a cidade de Salvador. As linhas cinza representam os membros do conjunto e a linha preta contínua o conjunto médio, para os prazos de (a) 2 dias, (b) 5 dias, (c) 10 dias e (d) 15 dias. A linha preta pontilhada representa os valores observados.

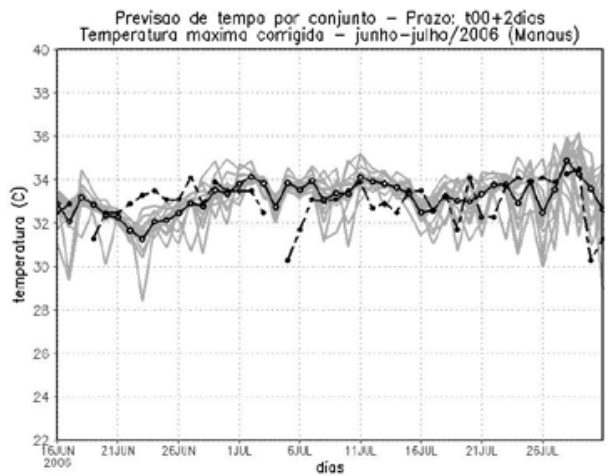

a)

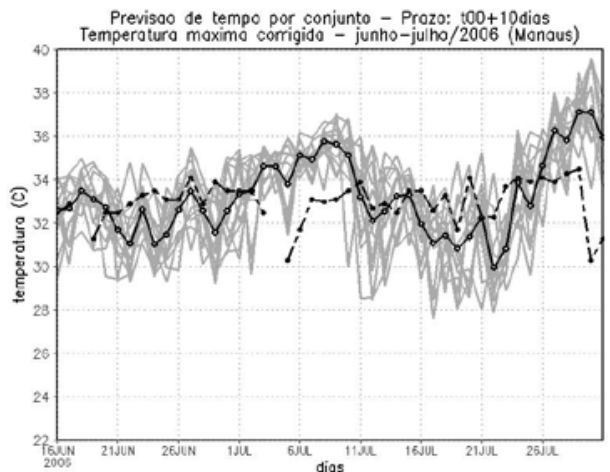

c)

Figura 17 - Idem a Figura 16, mas para Manaus.

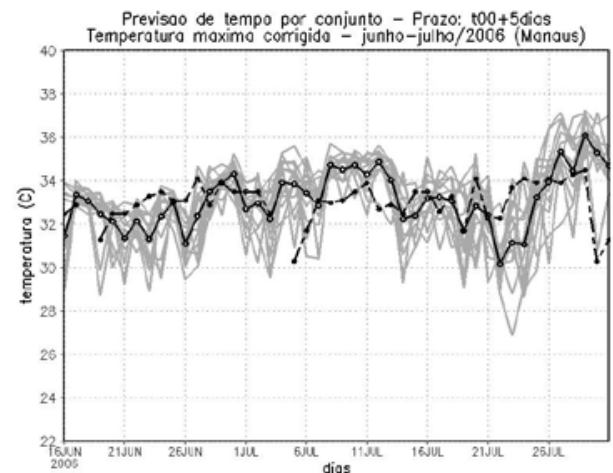

b)

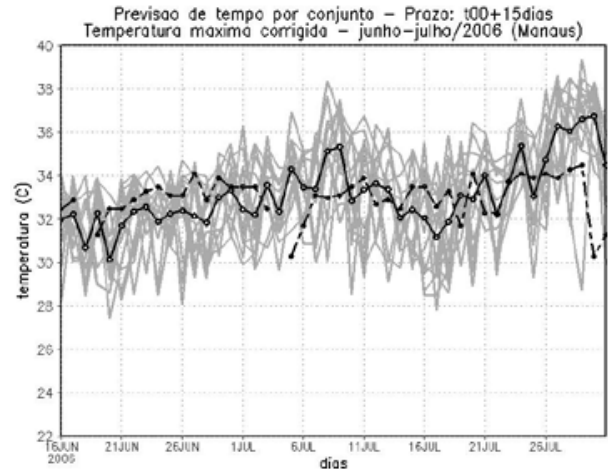

d)

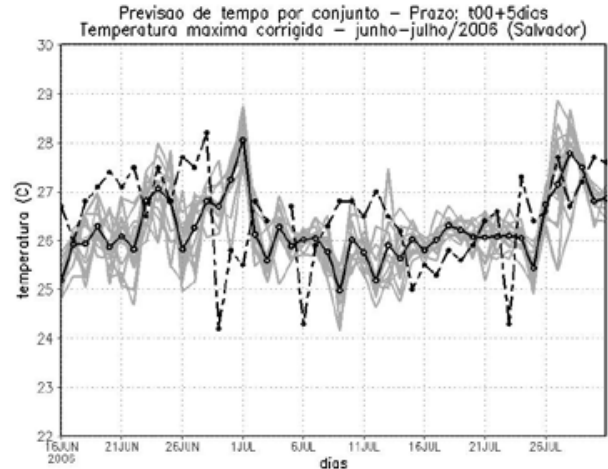

b)

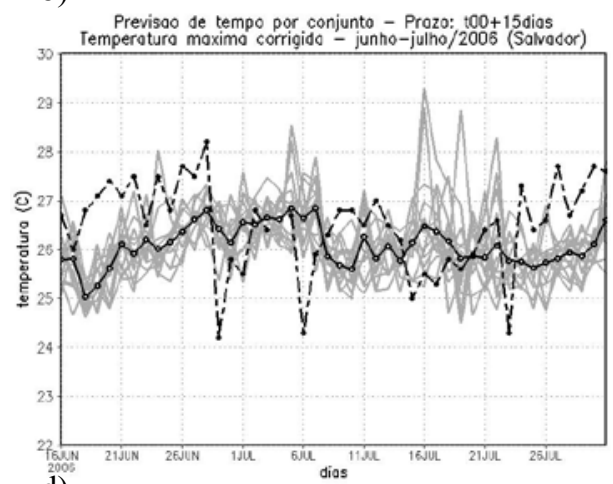

d) 


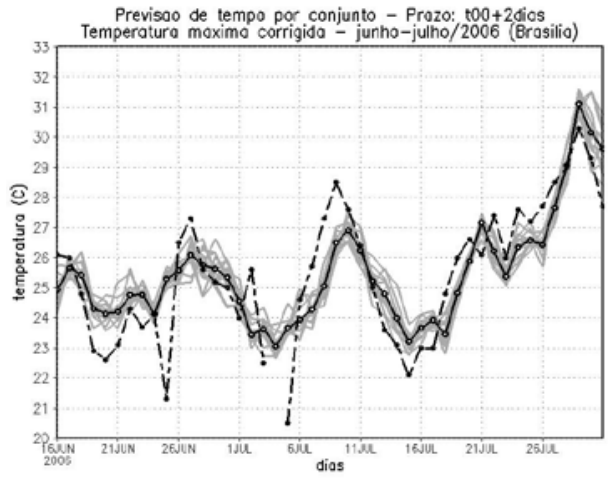

a)

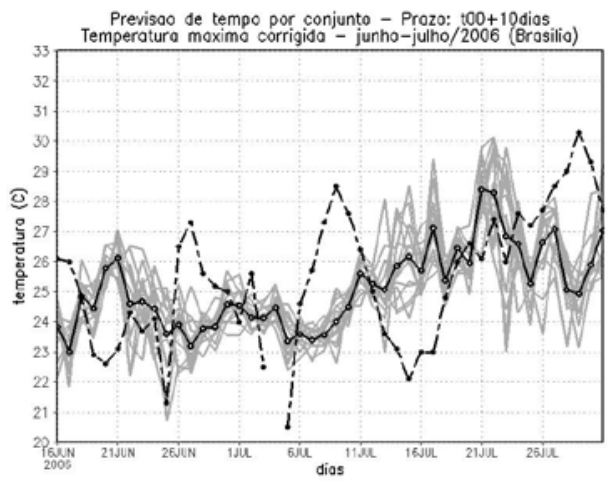

c)

Figura 18 - Idem a Figura 16, mas para Brasília.

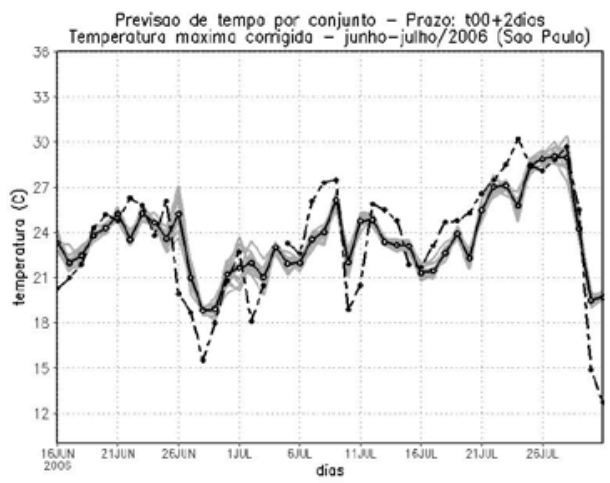

a)

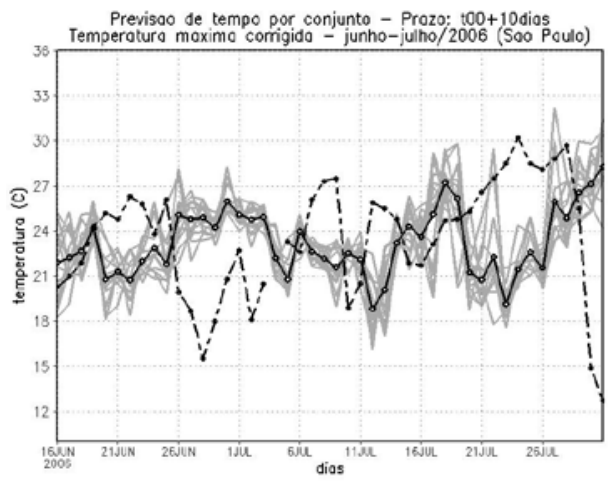

c)

Figura 19 - Idem a Figura 16, mas para São Paulo.

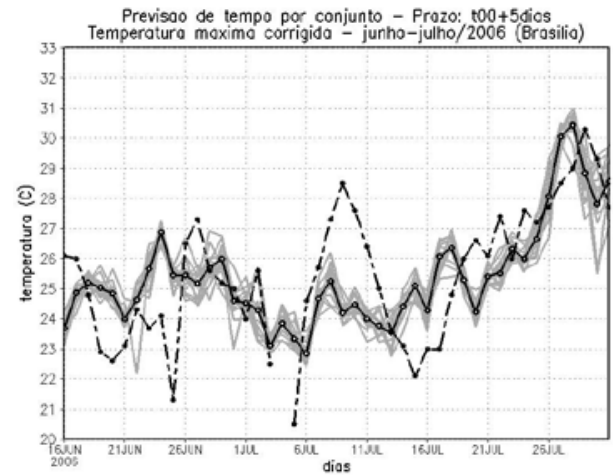

b)

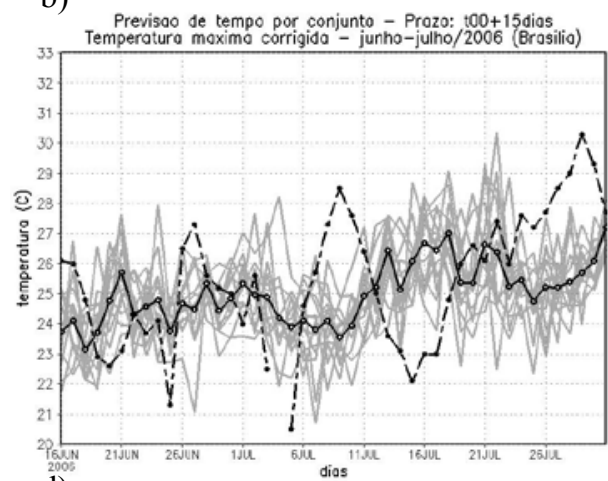

d)

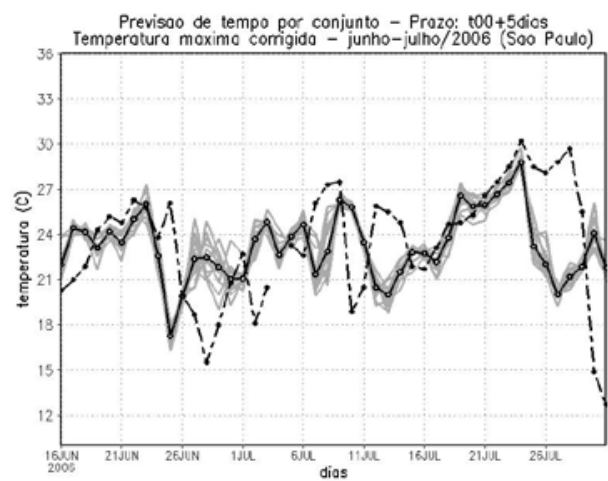

b)

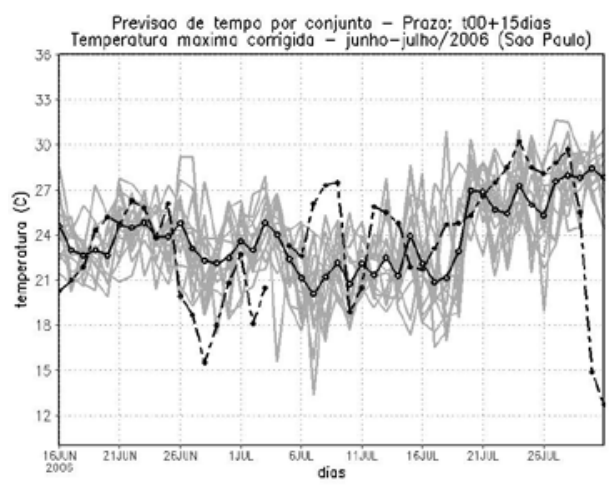

d) 


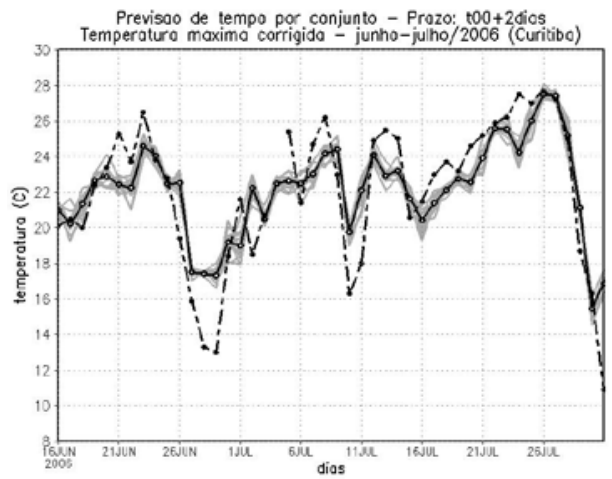

a)

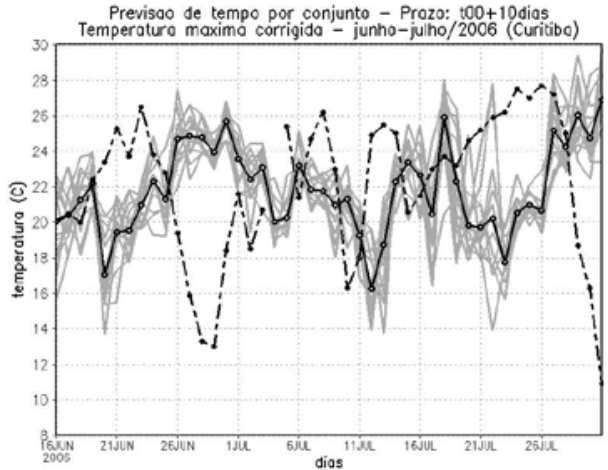

c)

Figura 20 - Idem a Figura 16, mas para Curitiba.

todas as capitais, as curvas de temperaturas observadas passaram a estar dentro das "plumas" de temperaturas previstas pelos membros do conjunto, exceto em alguns dias, em que foram observadas variações intensas de temperatura. Um bom exemplo de tal situação é Manaus, que antes da correção tinha outliers variando de 93,5\% (2 dias) até 91,3\% (15 dias) e após a correção estes valores passaram a ser de 39,1\% (2 dias) e 8,7\% (15 dias). Os melhores resultados foram obtidos para Manaus e Salvador, porém, para as demais capitais houve ganho significativo com as correções, com uma grande redução dos erros (Tabela 2).

A análise dos índices estatísticos de todas as capitais brasileiras indica que houve uma redução significativa no viés após a aplicação da correção, em todos os prazos de previsão. Em relação ao rms, nota-se, em geral, uma redução na sua magnitude. Apenas em Brasília, houve um pequeno aumento do rms nos prazos de 10 e 15 dias de previsão. Já em relação ao coeficiente de correlação de anomalias, obteve-se melhorias, após a correção, em praticamente todas as localidades, exceto em Brasília e Manaus onde a correlação entre a observação e a previsão do conjunto médio diminuiu. Para as demais capitais este coeficiente aumentou, principalmente para a previsão de curto prazo (2 dias), chegando a 0,88 em Curitiba. João Pessoa, Recife e Fortaleza apresentaram um aumento considerável nas correlações, após a correção, passando de 0,24, 0,30 e 0,12

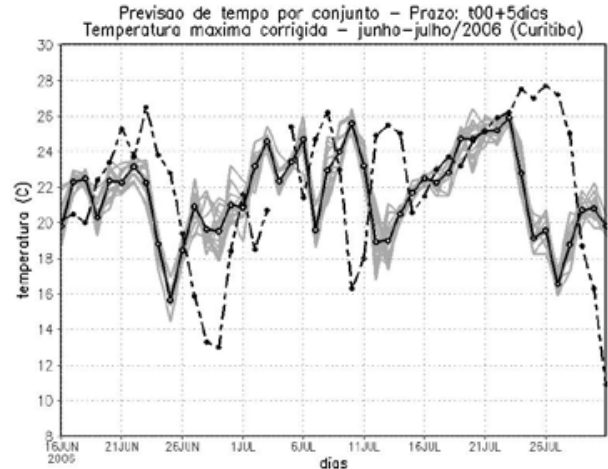

b)

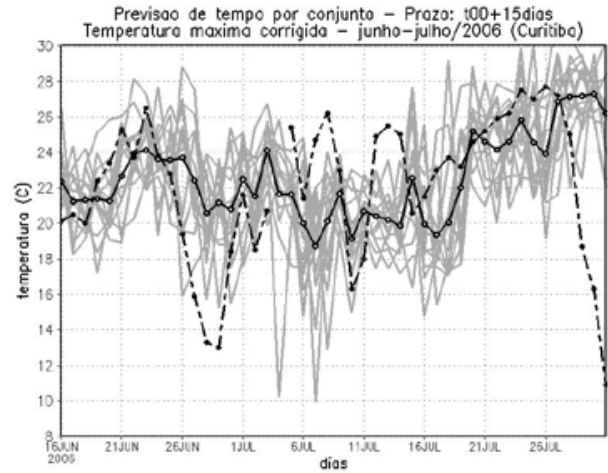

d)

para $0,59,0,57$ e 0,47 , respectivamente, para o prazo de 2 dias de previsão.

\section{CONCLUSÕES}

Neste estudo é apresentada uma metodologia para determinação das temperaturas mínimas e máximas, sobre o Brasil, a partir das informações do histórico do ponto de grade das previsões de tempo por conjunto do CPTEC. Além disso, é avaliado o impacto da aplicação de um método de correção estatístico, baseado na remoção do viés médio das 15 previsões mais recentes, com o intuito de reduzir os erros sistemáticos das previsões.

Os resultados mostraram que o método utilizado neste trabalho para a obtenção das temperaturas mínimas e máximas, pode ser utilizado operacionalmente para determinação deste diagnóstico. Observou-se que, em geral, as mínimas previstas apresentam-se um pouco mais quentes do que as observadas, exceto em Palmas, Boa Vista, Belo Horizonte e Goiânia onde o modelo prevê sistematicamente temperaturas mínimas levemente mais frias. Já as previsões das temperaturas máximas são, em geral, mais frias do que as observadas, exceto em Teresina, onde as máximas previstas estiveram levemente mais quentes para o prazo de 2 dias. Esta deficiência foi parcialmente 
resolvida a partir da remoção do viés médio das 15 previsões mais recentes, o que é constatado por melhores índices estatísticos das previsões corrigidas. Em algumas situações, como, por exemplo, as correções das previsões das temperaturas mínimas para Salvador e São Paulo para os prazos de previsão de 5 e 10 dias, respectivamente, o coeficiente de correlação de anomalias diminui, após as correções, no entanto nota-se que isto ocorre, geralmente, quando a correlação já é negativa e para prazos mais longos.

A correção das previsões apresentou melhores resultados para as capitais das regiões Sul, Sudeste e Centro-Oeste, tanto para as temperaturas mínimas quanto para as máximas. Nestes casos, verifica-se que a quantidade de outliers, ou seja, o número de casos em que as observações ficaram fora da pluma prevista pelos membros do conjunto diminui significativamente. Por outro lado, os resultados menos satisfatórios foram obtidos para as correções das temperaturas mínimias em algumas capitais da região Nordeste (Maceió, Recife e Fortaleza) quando o índice considerado é a correlação de anomalias, uma vez que a redução dos erros (viés e rms) nestas capitais foi significativa. Já para as correções das temperaturas máximas em algumas capitais da região Norte (Rio Branco, Cuiabá e Boa Vista) os índices estatísticos não indicaram um benefício sistemático de tais correções.

Este trabalho mostra que a determinação operacional das previsões de temperaturas mínimas e máximas a partir da previsão por conjunto pode ser útil, entretanto, é necessário que seja aplicada uma correção para diminuir os erros sistemáticos do modelo. A correção estatística, baseada na remoção do viés médio das 15 previsões mais recentes, utilizadas neste trabalho, mostrou-se bastante eficiente na redução dos erros do modelo.

\section{AGRADECIMENTOS}

Os autores agradecem o grupo de previsão operacional de clima do CPTEC pela disponibilização dos dados observados e aos dois revisores anônimos que contribuíram para melhorar a qualidade do artigo. O primeiro autor agradece ao $\mathrm{CNPq}$ pelo apoio financeiro (Processo n $384320 / 2006-6$ ).

\section{REFERÊNCIAS BIBLIOGRÁFICAS}

BONATTI, J.P. Modelo de circulação geral do CPTEC. [on line]. Climanálise Especial 10 anos, 26, 5p. [http://www.cptec. inpe.br/products/climanalise/cliesp10a/bonatti.html], 1996.

CARDOSO, A O. et al... Correção estatística das previsões de tempo por conjunto do MGCA CPTEC/COLA através da remoção do viés. Anais do XIV Congresso Brasileiro de Meteorologia, Florianópolis-SC, 2006.
CLIMANALISE: Climatologia de Precipitação e Temperatura. Edição especial, 1996.

BONATTI, J.P., Rao, V.B., Silva Dias, P.L. Estudo observacional da propagação para oeste do fenômeno Catarina e sua simulação com modelo global de alta resolução. Anais do XIII Congresso Brasileiro de Meteorologia, Fortaleza-CE, 2004.

COUTINHO, M. M. Previsão por conjuntos utilizando perturbações baseadas em componentes principais. São José dos Campos, SP. Dissertação (Mestrado em Meteorologia). Instituto Nacional de Pesquisas Espaciais. São José dos Campos, 1999.

ECKEL, F.A., Mass, C. F. Aspects of effective mesoscale short-range ensemble forecasting.Wea. Forecasting, 20, p. 328-350, 2005.

FEDOROVA, N. Meteorologia Sinótica. Pelotas: UFPel: Ed. Universitária, 1999.

GRIMIT, E.P. et al.. The contiuous ranked probalitity score for circular variables and its application to mesoscale forecast ensemble verfication. Quart. J. Roy. Met. Soc., v. 132, p. 1-17, 2006.

KINTER, J. L. et al.: The COLA atmosphere-biosphere general circulation model Volume 1: Formulation. Center for OceanLand-Atmosphere Studies. Calverton, MD, COLA Staff, Report N.o 51, 1997

MENDONÇA, A. M.; Bonatti, J. P.: O Sistema de Previsão de Tempo Global por Ensemble do CPTEC. Anais do XII Congresso Brasileiro de Meteorologia, Foz do Iguaçu-PR, 2002.

SILVA DIAS, P.L.; Moreira, D. S. The Master Super Model Ensemble System (MSMES). Proceedings of 8 ICSHMO, Foz do Iguaçú, Brazil, April 24-28, INPE, p. 1751-1757, 2006.

REYNOLDS, C. A., P. J. Webster, E. Kalnay, 1994: Random Error Growth in NMC's Global Forecasts. Mon. Wea. Rev., 122, 1281-1305.

SILVA, M. C. L. et al.:Previsão de Temperaturas Mínimas para o Centro-Sul do Brasil Utilizando a Previsão de Tempo por Ensemble do CPTEC. Anais do XIV Congresso Brasileiro de Meteorologia, Florianópolis-SC, 2006.

SIVILLO, J. K.; Ahlquist; J. E.; Toth, Z. An Ensemble Forecasting Primer. Weather and Forecasting, v. 12, 809818, 1997.

VAREJÃO-SILVA, M. A. Meteorologia e Climatologia. Brasília, DF: Ed. Pax, INMET, 2001.

WILKS, D.S.: Statistical Methods in the Atmospheric Sciences: An Introduction. v. 59. Academic Press, 1995.

ZHANG, Z., KRISHNAMURTI, T.N. A perturbation method for hurricane ensemble predictions. Mon. Wea. Rev., v. 127, p. 447-469, 1999. 